\title{
Using Finite Element and Ultrasonic Method to Evaluate Welding Longitudinal Residual Stress through the Thickness in Austenitic Stainless Steel Plates
}

\author{
Yashar Javadi ${ }^{1}$ \\ ${ }^{1}$ Department of Mechanical Engineering, Amirkabir University of Technology, 424 Hafez Ave.,15914, Tehran, Iran. \\ yashar javadi@aut.ac.ir
}

Mehdi Akhlaghi ${ }^{2 *}$

${ }^{2}$ Department of Mechanical Engineering, Amirkabir University of Technology, 424 Hafez Ave.,15914, Tehran, Iran. $\underline{\text { makhlagi@aut.ac.ir }}$

Mehdi Ahmadi Najafabadi ${ }^{3}$

${ }^{3}$ Department of Mechanical Engineering, Amirkabir University of Technology, 424 Hafez Ave.,15914, Tehran, Iran. ahmadin@aut.ac.ir

\begin{abstract}
This paper uses a 3D thermo-mechanical finite element analysis to evaluate welding residual stresses in austenitic stainless steel plates of AISI 304L. The finite element model has been verified by the hole drilling method. The validated finite element (FE) model is then compared with the ultrasonic stress measurement based on acoustoelasticity. This technique uses longitudinal critically refracted $\left(L_{C R}\right)$ waves that travel parallel to the surface within an effective depth. The residual stresses through the thickness of plates are evaluated by four different series ( $1 \mathrm{MHz}, 2 \mathrm{MHz}, 4 \mathrm{MHz}$ and $5 \mathrm{MHz}$ ) of transducers. By combining FE and $L_{C R}$ method (known as FELCR method) a 3D distribution of residual stress for the entire of the welded plate is presented. To find the acoustoelastic constant of the heat affected zone (HAZ), a metallographic investigation is done to reproduce HAZ microstructure in a tensile test sample. It has been shown that the residual stresses through the thickness of stainless steel plates can be evaluated by $F E L_{C R}$ method.
\end{abstract}

* Corresponding author's e-mail: makhlagi@aut.ac.ir Tel: +98 216454 3419, Fax: +98 2166419736.

Keywords: Finite Element Welding Simulation; Ultrasonic Stress Measurement; Welding Residual Stress; Austenitic Stainless Steel; Through Thickness Stress; Acoustoelasticity. 


\section{Introduction}

Residual stresses of welded structures are produced as a result of non uniform thermal expansions and contractions during the welding processes. Nondestructive measurement of residual stress is important to optimize the structures' design and control their mechanical strength. Unfortunately, there is no reliable method that nondestructively gives complete satisfaction in the in-situ stress monitoring of the welded structures. Material, geometry, surface quality, cost, and accuracy of the measurement are some of the parameters that must be taken into account in choosing a proper method. Therefore, the development of several methods like X-ray diffraction, incremental hole drilling, and the ultrasonic waves are inevitable [1].

Stress measurement by ultrasonic waves is a nondestructive, easy to use, and reasonably inexpensive method recently used in some industrial applications. However, it is slightly sensitive to the microstructure effects like grain size [2], carbon rate [3], texture [4], and structure [5] and also to the operating conditions (temperature [6], coupling [7], etc.). The ultrasonic evaluation of the residual stresses requires the division between the microstructure and the acoustoelastic effects which are simultaneously reasons of changing in ultrasonic properties of the structure materials.

Welding simulation by Finite Element (FE) has become a popular method for the prediction of welding residual stresses and deformations. Earlier studies of welding simulation accounted for the nonlinearities caused by temperature dependent material properties and plastic deformations [8]. The majority of those studies, due to weakness in the computational capabilities of the previous computers, were limited to two-dimensions on the plane perpendicular to the welding direction. Good agreements have been observed between the numerical predictions and experimental results ([9]-[10]) which encourage using FE welding simulation in residual stress evaluation.

\section{Theoretical Background}

\subsection{Ultrasonic Stress Measurement}

Ultrasonic stress measurement is based on the linear relationship between the velocity of ultrasonic wave and the stress of material. This relationship, within the elastic limit, is the acoustoelastic effect which says that ultrasonic wave flight time varies with stress. The longitudinal critically refracted $\left(L_{C R}\right)$ wave is a longitudinal ultrasonic wave which can travel parallel to the surface. The $L_{C R}$ method uses a special longitudinal bulk wave mode, as shown in Fig. 1, mainly propagating beneath the surface at a certain depth. When a longitudinal wave passes through an interface between two materials, there is an incident angle that makes the angle of refraction for the wave $90^{\circ}$. This is known as the first critical angle which is calculated $28^{\circ}$ from the Snell's law when the wave moves from PMMA wedge to the steel (Fig. 1). It is shown by Egle and Bray [11] that sensitivity of the $L_{C R}$ waves to the strain is highest amongst the other types of ultrasonic waves.

The relationship between the velocity of the longitudinal waves which travel parallel to load direction and the strain $(\alpha)$ is expressed by the following equation:

$$
\rho_{0} V_{11}^{2}=\lambda+2 \mu+(2 l+\lambda) \theta+(4 m+4 \lambda+10 \mu) \alpha_{1}
$$

where $\rho_{0}$ is the initial density; $V_{11}$ is the wave velocity of longitudinal wave which propagates parallel to load; $\lambda, \mu$ the second order elastic constants (Lame's constants); I and $m$ are the third order elastic constants; $\vartheta=\alpha_{1}+\alpha_{2}+\alpha_{3}$ which $\alpha_{1}, \alpha_{2}$ and $\alpha_{3}$ are components of the homogeneous triaxial principal strains. For a state of uniaxial stress, 
$\alpha_{1}=\varepsilon, \alpha_{2}=\alpha_{3}=-v \times \varepsilon$, where $\varepsilon$ is the strain in the direction 1 and $v$ is the Poisson's ratio. Using these values, Eq. (1) becomes:

$$
\rho_{0} V_{11}^{2}=\lambda+2 \mu+\left[4(\lambda+2 \mu)+2(\mu+2 m)+v \mu\left(1+\frac{2 \lambda}{\mu}\right)\right] . \varepsilon
$$

The variation of the velocity with the strain is called as "relative sensitivity" and can be calculated by Eq. (3).

$$
\frac{d V_{11} / V_{11}}{d \varepsilon}=2+\frac{(\mu+2 m)+v \mu(1+2 l / \lambda)}{\lambda+2 \mu}=L_{11}
$$

where $L_{11}$ is the dimensionless acoustoelastic constant for $L_{C R}$ waves which should be measured by the uniaxial tensile test.

Eq. (3) is rearranged to calculate the stress variation in terms of time-of-flight ( $\left.d t / t_{0}\right)$, as shown in the Eq. (4).

$$
d \sigma=\frac{E\left(d V_{11} / V_{11}\right)}{L_{11}}=\frac{E}{L_{11}}\left(d t / t_{0}\right)
$$

, where $d \sigma$ is the stress variation, $E$ is the elasticity modulus and $t_{0}$ is the time for the wave which travels through a stress free path in the material being investigated. For a fixed probe distance, the travel time of the $L_{C R}$ wave decreases in compressive stress and increases in tensile stress field. The acoustoelastic constant ( $\left.L_{11}\right)$ links the stress and the velocity or change in travel time.

\subsection{Finite Element Welding Simulation}

Numerical simulation of welding residual stresses needs to accurately take into account the interactions between heat transfer, metallurgical transformations and mechanical fields. The phenomena involved in the heat input such as arc, material interactions, as well as, fluid dynamics in the weld pool are not precisely described. From the thermo-mechanical point of view, the heat input can be seen as a volumetric or surfaced energy distribution, and the fluid flow effect, which leads to homogenized temperature in the molten area, can be simply taken into account by increasing the thermal conductivity over the melting temperature. As no metallurgical transformation occurs in the austenitic stainless steel (304L), the detailed modeling of the melting is not considered. Heat transfers in solids are described by the heat equation as following:

$\rho \frac{d H}{d t}-\operatorname{div}(k \nabla T)-Q=0$

$$
k \nabla T . n=q(T, t) \quad \text { on } \partial \Omega_{q}
$$

$$
T=T_{p}(t) \quad \text { on } \partial \Omega_{t}
$$

, where $\rho, H, K$ and $T$ are density, enthalpy, thermal conductivity and temperature respectively. $Q$ represents the internal heat source. In Eq. (6), $\mathrm{n}$ is the outward normal vector of domain $\partial \Omega$ and $q$ the heat flux density that can rely on temperature and time to model convective heat exchanges on the surface and $T_{p}$ is a prescribed temperature. In the present study, the double ellipsoid heat source pattern proposed by Goldak et al. [12] is used. The Goldak equations for the front and rear heat source are expressed by the Eq. 8 and Eq. 9 respectively: 
$q_{f}(x, y, z)=\frac{6 \sqrt{3} f_{f} Q}{a b c_{f} \pi^{3 / 2}} e^{\left(-3 x^{2} / a^{2}\right)} e^{\left(-3 y^{2} / b^{2}\right)} e^{\left(-3 z^{2} / c^{2}\right)}$

$q_{r}(x, y, z)=\frac{6 \sqrt{3} f_{r} Q}{a b c_{r} \pi^{3 / 2}} e^{\left(-3 x^{2} / a^{2}\right)} e^{\left(-3 y^{2} / b^{2}\right)} e^{\left(-3 z^{2} / c^{2}\right)}$

, where $x, y$ and $z$ are the local coordinates of the double ellipsoid model aligned with the welded plate; $f_{f}$ and $f_{r}$ are parameters which give the fraction of the heat deposited in the front and rear parts, respectively. $Q$ is the welding energy which is calculated by knowing the welding current and voltage and considering the arc efficiency. The parameter $a$ is one-half the width of melted zone; $b$ is depth of the melted zone; $c_{f}$ and $c_{r}$ are the front and behind section dimensions of the heat source respectively. In this study, the parameter $a$ and $b$ are measured $6.5 \mathrm{~mm}$ and $7 \mathrm{~mm}$ for the main weld respectively, while they are $5.5 \mathrm{~mm}$ and $3 \mathrm{~mm}$ for the back weld. The front section dimension of the heat source $\left(c_{f}\right)$ is assumed equal to $a$ and the rear section $\left(c_{r}\right)$ is equal to $4 \times a$. The relations $2 /(1+$ $\left.c_{r} / c_{f}\right)$ and $2 /\left(1+c_{f} / c_{r}\right)$ are used to calculate the $f_{f}$ and $f_{r}$ respectively. The moving heat source is modelled by a user subroutine in the ANSYS software.

In the thermal analysis, the boundary conditions include the radiation and convection to the environment from all of the plate surfaces except the symmetry surface and the area under the heat source. Radiation losses are significant for higher temperatures near the weld zone, while convection losses are higher for lower temperatures nodes away from the weld. A user subroutine is employed to simulate the combined thermal boundary condition while the heat convection coefficient is assumed $8 \mathrm{~W} / \mathrm{m}^{2} \mathrm{~K}$. The structural constraints are also applied on the symmetry section of weld as the mechanical boundary conditions.

The mechanical analysis is based on the usual equations of the static equilibrium. As the plastic dissipation is neglected in the thermal analysis, thermal and mechanical analysis can be treated separately. The temperature fields computed by the thermal analysis, is used in the mechanical analysis. The materials are supposed to follow an elastic-plastic behavior with isotropic hardening. The material parameters, young's modulus, poisson's ratio, yield stress, strain hardening and heat expansion coefficient are temperature dependent.

Material modeling has always been a serious issue in the simulation of welding because of the scarcity of material data at elevated temperatures. Some simplifications and approximations are typically introduced to cope with this problem. These simplifications are necessary because of both lack of data and numerical problems when trying to model the actual high-temperature behavior of the material [13]. The material properties of 304L stainless used in the finite element analysis is extracted from X.K.Zhu et al. [14].

The problem is formulated as a successively coupled thermal stress analysis. First, a non-linear thermal analysis is performed to calculate the temperature history of the entire domain. Then, the results of the thermal analysis are applied as a thermal body load in a non-linear mechanical analysis determining residual stress and distortion. The finite element (FE) models for both thermal and structural analysis are the same. The general-purposed FE program ANSYS is used for the analysis. A full Newton-Raphson iterative solution technique with direct sparse matrix solver is employed for obtaining a solution. During the thermal analysis, the temperature and the temperature dependent material properties alter very rapidly. Thus, the full Newton-Raphson technique with using modified material properties is believed to give more precise results.

A conventional technique named "Element Birth and Death" [15] is used for modelling of the deposited weld. A complete FE model is generated in the start of the analysis. However, all elements representing the deposited weld except elements for the tack welds are deactivated by assigning them a very low stiffness. During the thermal analysis, all the nodes of deactivated elements (excluding those shared with the base metal) are also fixed at room temperature till the birth of the respective elements. Deactivated elements are reactivated sequentially when they 
come under the effect of the welding torch. Linear elements are preferred than higher-order elements in nonlinear problems of this type [16]. Here, eight-noded-brick elements with linear shape functions are used in the FE modeling.

A meshing investigation is done to find the most proper mesh according to the mesh size and accuracy of the FE results. The basic mesh size is shown in Fig. 2, while some finer and coarser meshing models are studied and the results are compared with the experimental measurements. Selecting the most effective mesh size leads to the accurate results along with time-consuming calculations.

\section{Experimental Procedures}

\subsection{Sample Description}

Tested material is austenitic stainless steel plate (A240-TP304L). Single pass butt-weld joint geometry with a backweld pass and without root gap is used. Two $600 \times 250 \times 10 \mathrm{~mm}$ normalized and rolled plates are welded in V-groove $\left(90^{\circ}\right.$ included angle). Back and the main weld passes are performed by submerged arc welding (SAW) process with the specifications mentioned in Table 1. The plates are tacked weld in two points while no clamps are employed during the welding process. The face and the root reinforcement are removed to be adapted to the shape of ultrasonic measurement devices. A $30000 \mathrm{rpm}$ hand grinder is utilized to remove the reinforcements while water cooling is simultaneously employed to control the temperature. The cooling process along with very low depth of cut, keeps the grinding temperature less than $50 \mathrm{C}$ to prevent the creation of new thermal stresses.

\subsection{Measurement Device}

The measurement device, shown in Fig. 3, includes an ultrasonic box, computer and time of flight (TOF) measuring element. Also, a measuring table is needed to move TOF measuring element accurately and with enough stability. The ultrasonic box is a $100 \mathrm{MHz}$ ultrasonic testing device which has synchronization between the pulser signal and the internal clock, which controls the A/D converter. This allows very precise measurements of the time of flight better than 1ns. TOF measuring element includes three normal transducers assembled on an integrated wedge to measure the time of flight. A poly methyl methacrylate (PMMA) material, under the trademark Plexiglas, was cut by laser cutting to construct the wedge. A three-probe arrangement was used, with one sender and two receivers in order to eliminate environment temperature effect to the travel time. Twelve transducers in four different frequencies were used where their nominal frequencies were $1 \mathrm{MHz}, 2 \mathrm{MHz}, 4 \mathrm{MHz}$ and $5 \mathrm{MHz}$. Using different frequencies helps to evaluate residual stresses through the thickness of the plates. The diameter of all the piezoelectric elements was $6 \mathrm{~mm}$.

\subsection{Determination of $L_{C R}$ Penetration Depth}

When the $L_{C R}$ technique is applied to an application with limited wall thickness, the penetration depth of the $L_{C R}$ wave is expected to be a function of frequency. Since there is no definite relation for $L_{C R}$ depth and frequency, it should be measured experimentally. Four different frequencies have been used in this work to evaluate the residual stress through the thickness of the plates. Therefore the depth of all frequencies should be exactly measured. The setup which is shown in Fig. 4 is used to measure the penetration depth of the $L_{C R}$ wave. Two transducers as sender and receiver (No. 6 and 7) with the same frequency are used to produce the $L_{C R}$ wave. A slot is performed between the transducers by milling tool (No. 8) to create an obstacle in the path of the $L_{C R}$ wave. The depth of the slot is increased step by step and the amplitude of the $L_{C R}$ wave is measured in each step. When the amplitude of the $L_{C R}$ wave is equal to the noise, milling process is stopped and the depth of slot represents the penetration depth of the $L_{C R}$ waves for the tested frequency. The material is the same as the welded plates. The measured penetration depths of $L_{C R}$ wave are $5 \mathrm{~mm}, 2 \mathrm{~mm}, 1.5 \mathrm{~mm}$ and $1 \mathrm{~mm}$ for the transducers with nominal frequencies of $1 \mathrm{MHz}, 2 \mathrm{MHz}, 4 \mathrm{MHz}$ and $5 \mathrm{MHz}$ respectively. 


\subsection{Evaluation of the Calibration Constants}

To evaluate the calibration constants (acoustoelastic constant and free stress time-of-flight), the calibration samples were taken from both sides of the plates. Eight rectangular tension test specimens were extracted to determine the acoustoelastic constant $\left(L_{11}\right)$ with an average of the results as following:

a) Four specimens were extracted from both sides of the plates in the parent material (PM) zone.

b) Two specimens were extracted from the melted zone (MZ).

c) Two specimens were extracted from the parent material and then were heat treated to reproduce the microstructure of the heat affected zone (HAZ). Metallographic analysis of the weld shows that the heat affected zone is not large enough to extract tensile test sample (Fig. 5). Therefore 12 metallographic samples were prepared from tensile test specimens. Each one has experienced different annealing temperature, annealing time, cooling rate and cooling environment. Since no microstructure phase change occurred in the HAZ during the welding process, the criterion is austenitic grain size. From this point, the best agreement was found for the sample annealed at $1200^{\circ} \mathrm{C}$ for $7 \mathrm{~min}$ followed by an air cooling (Fig. 6). The grain size of HAZ and simulated sample were close to G5.5 according to the ASTM: E112 (standard test methods for determining average grain size).

To evaluate the residual stress according to Eq. (4), the value $t_{0}$ is measured directly from the stress-free samples and the acoustoelastic constant $\left(L_{11}\right)$ is deduced experimentally from a uniaxial tensile test associated with an ultrasonic measurement (see Fig. 7). The results of tensile test are shown in Fig. 8 for $1 \mathrm{MHz}$ transducer and also the $L_{11}$ for all of the transducers listed in Table 2. The acoustoelastic constant of HAZ is less than the PM while the $\mathrm{MZ}$ constant is the maximum. Similar results were previously reported in the acoustoelastic constant measurement of P335 steel [17]. The stress-free samples are the same as the tensile test specimens which are stress relieved by heat treatment. The samples are constructed with the dimensions of Sheet type ( $0.5 \mathrm{in}$. wide) according to the ASTM: E8 standard while the width of grip section and reduced section are $20 \mathrm{~mm}$ and $12.5 \mathrm{~mm}$ respectively.

\section{Results and Discussion}

In this study, the 3D finite element analysis for welding simulation is verified by hole-drilling method. The validated finite element model can be used to predict the 3D distribution of residual stresses through the plate thickness. The 3D distribution of residual stresses is measured with four set of transducers with different frequencies. To compare ultrasonic with FE results, eight test sections are selected as shown in Fig. 9. The test sections are selected according to the plate surface deformations to employ the most flat sections and facilitate ultrasonic measurement. Since the maximum $L_{C R}$ depth is $5 \mathrm{~mm}$ for $1 \mathrm{MHz}$ transducer, the investigated $10 \mathrm{~mm}$ thickness plates cannot be inspected only from one side. Therefore, all of the measurements are performed for the top and bottom surface (referred to as Main-Weld and Back-Weld respectively) of the plates.

The wave speed for $L_{C R}$ waves is affected by the average stress in a layer which may be a few millimeters thick [18]. It means that ultrasonic method measures the average of stresses in determined depths. For example, the $1 \mathrm{MHz}$ $L_{C R}$ wave travels in $5 \mathrm{~mm}$ from the surface and gives the average of residual stress in this zone. Therefore, the FE residual stresses for all the nodes located in $5 \mathrm{~mm}$ under the surface are extracted and their averages are calculated to compare with measurements performed by the $1 \mathrm{MHz} L_{C R}$ wave. Fig. 10 shows the FE distribution of residual stress through the thickness in the line of $Z=300 \mathrm{~mm}$ and $X=0 \mathrm{~mm}$ (which is the middle line of the weld length). The residual stress in the top surface is $192.11 \mathrm{MPa}$ while it is $174.75 \mathrm{MPa}$ in the bottom surface according to Fig. 10. The boundary separating main and back weld is about $7 \mathrm{~mm}$ from the top surface where the minimum of residual stress occurs. To compare with ultrasonic measurements, the averages of residual stress in the middle line are listed in Table 3 according to the test frequencies.

6 
The results of the finite element method are shown in Fig. 11 for different depths correspond to the integration points of the elements. These results are in good agreement with welding logic which says the maximum of tensile residual stress is produced in the weld centerline and it will be transformed to compressive stress near the HAZ and finally free stress zone in the parent material [19]. The results which are shown here are the exact quantity of the residual stresses in the determined depth. In this figure, the depths (which are mentioned on the right side of the charts) are the distance from the top surface and are selected to divide the main and back weld to the four equal depths. The Fig. 11 shows quality variation of the longitudinal residual stress from tensile stress in the top surface of the weld to the compressive stress in the root of the main and back weld. However, the results shown in Fig. 11 cannot be compared with the ultrasonic results because they are exact results while ultrasonic method measures the average of residual stresses. Therefore, the averages of residual stresses are calculated by the FE and are shown in Fig. 12. These averages are calculated according to the penetration depth of available test frequencies.

To compare FE results with ultrasonic measurements, it is needed to verify the FE model with the experimental results. The validation of the thermal analysis is done by comparison of the real melted zone dimension, shown in Fig. 5 , and the MZ size estimated by FE analysis. The mechanical analysis is also verified by hole-drilling method according to Fig. 13. The average results of FE residual stress in $2 \mathrm{~mm}$ from the surface are in good agreement with those of hole-drilling. It should be noticed that, hole-drilling method is also gives the average of residual stress measured along the $2 \mathrm{~mm}$ depth hole. The hole-drilling method is performed in four different points based on the characterizations described in ASTM: E837 while the measurement setup and holes position are shown in Fig. 14.

The distribution of longitudinal residual stress in the weld line is shown in Fig. 15. It shows rapid changes in the weld start and end point and a mild increase in the final third of the weld line. Similar distribution of longitudinal residual stress along the weld length, was previously reported in FE analysis of SAE 1020 steel plate [20].

The results of ultrasonic measurements are shown in Fig. 16-Fig. 19 and Fig. 21-Fig. 24 for the main and back weld respectively. The 3D distribution of ultrasonic measurement is also shown in Fig. 20 and Fig. 25. All of the results of ultrasonic measurements are compared with finite element analysis showing an acceptable agreement. Given the large number of graphs to compare the eight test sections, only the results of the last test section (Test Section 8 , near the welding end point) and the middle test section (Test Section 5, near the hole-drilled zone) are discussed.

Fig. 16, Fig. 17, Fig. 18 and Fig. 19 show the $L_{C R}$ results performed by $5 \mathrm{MHz}, 4 \mathrm{MHz}, 2 \mathrm{MHz}$ and $1 \mathrm{MHz}$ transducers respectively and comparison with the finite element data in the main weld. The maximum deviation of ultrasonic and FE results by $5 \mathrm{MHz}$ is $44.72 \mathrm{MPa}$ in the center of the weld at the Test Section 8. This large deviation is because of the improper effect of welding end point which can not accurately be considered in finite element simulation. However, improper effect of welding end point cannot be observed in the $4 \mathrm{MHz}, 2 \mathrm{MHz}$ and $1 \mathrm{MHz}$ results. It means that this is a surface effect and do not penetrate more than $1 \mathrm{~mm}$ (which is the measured penetration depth of $5 \mathrm{MHz} L_{C R}$ wave). The deviations of other points by $5 \mathrm{MHz}$ do not exceed $\pm 30 \mathrm{MPa}$ and also it is $\pm 18 \mathrm{MPa}$, $\pm 16 \mathrm{MPa}$ and $\pm 11 \mathrm{MPa}$ for the test performed by $4 \mathrm{MHz}, 2 \mathrm{MHz}$ and $1 \mathrm{MHz}$ transducers respectively. Comparison between different test frequencies shows that the $L_{C R}$ waves work more accurately, when lower frequencies are employed. It means that the deviation of $L_{C R}$ waves and $\mathrm{FE}$ results by $5 \mathrm{MHz}$ is higher than the deviation by $4 \mathrm{MHz}$ and the minimum occurs at $1 \mathrm{MHz}$. Higher error for higher frequencies can be justified by the fact that the low frequency transducers produce sharp and more powerful echo in the receiver than high frequency transducers. Therefore it is necessary to increase the "Gain" by using higher frequencies, which will lead to less resolution and higher measuring error in the time of flight.

The maximum of residual stress measured by $5 \mathrm{MHz}, 4 \mathrm{MHz}, 2 \mathrm{MHz}$ and $1 \mathrm{MHz}$ transducers is $225.56 \mathrm{MPa}, 233.31$ $\mathrm{MPa}, 214.32 \mathrm{MPa}$ and $159.56 \mathrm{MPa}$ respectively. It means that, $L_{C R}$ wave can penetrate in the depth of stainless steel and measure the residual stress of the bulk. The potential of the $L_{C R}$ waves to measure the bulk stresses, is also confirmed by the majority of previous studies $[1,11,17-18,21-24]$ 
Comparing ultrasonic with FE results show less agreement in HAZ (7-9 mm distance from the weld centerline) because of the small width in HAZ (about $1.5 \mathrm{~mm}$ ) and also the change of dimensions through the thickness. The width of wedge is $15 \mathrm{~mm}$ which is about 10 times of the HAZ width. If the wedge moves with $0.5 \mathrm{~mm}$ steps over the HAZ, it will be $15 / 0.5+(1.5 / 0.5)=33$ points which $\mathrm{HAZ}$ and wedge have contact. A combination of $\mathrm{HAZ}, \mathrm{MZ}$ and PM acoustoelastic constant is applied for all of the 33 points. For example if $1.5 \mathrm{~mm}$ of wedge width is over the HAZ and the other $13.5 \mathrm{~mm}$ is on the PM, the acoustoelastic constant is calculated according to $1.5 / 15=10 \%$ of HAZ constant and $90 \%$ of PM constant. Another practical limitation in ultrasonic measurement of the HAZ is changing dimensions through the thickness because of welding groove shape. According to the groove shape shown in Fig. 5, for example in $5 \mathrm{~mm}$ distance in the right of the weld centerline:

1) The $5 \mathrm{MHz} L_{C R}$ wave travels $1 \mathrm{~mm}$ under the surface where about $80 \%$ of wave width is propagated in the $M Z$ and the other $20 \%$ in the HAZ.

2) The $4 \mathrm{MHz} L_{C R}$ wave travels $1.5 \mathrm{~mm}$ under the surface where about $65 \%$ of wave width is propagated in the $\mathrm{MZ}$ and the other $35 \%$ in the HAZ.

3) The $2 \mathrm{MHz} L_{C R}$ wave travels $2 \mathrm{~mm}$ under the surface where about $50 \%$ of wave width is propagated in the $\mathrm{MZ}$ and the other $50 \%$ in the HAZ.

4) The $1 \mathrm{MHz} L_{C R}$ wave travels $5 \mathrm{~mm}$ under the surface where about $25 \%$ of wave width is propagated in the $M Z, 25 \%$ in the $H A Z$ and $50 \%$ in the PM.

Therefore the acoustoelastic constant is calculated according to $80 \%$ of MZ constant and $20 \%$ of HAZ constant for 5 $\mathrm{MHz} L_{C R}$ wave when the wedge center is located in $\mathrm{X}=5 \mathrm{~mm}$. The same considerations should also be used for the other frequencies mentioned above. The practical limitations explained, increase the calculations and measurement error of residual stress obtained from ultrasonic evaluation in the HAZ.

Fig. 20 shows the ultrasonic 3D distribution of longitudinal residual stress of the main weld. Comparing the results with finite element analysis shows good agreement between 3D distribution of FE and ultrasonic results. However, some specifications are different, for example the tensile stress rise near the welding end point (Fig. 15) cannot be observed in ultrasonic results because of experimental error.

Fig. 21, Fig. 22, Fig. 23 and Fig. 24 show the $L_{C R}$ results performed by $5 \mathrm{MHz}, 4 \mathrm{MHz}, 2 \mathrm{MHz}$ and $1 \mathrm{MHz}$ transducer respectively and comparison with the finite element data in the back weld. The maximum deviation of ultrasonic and FE results by $5 \mathrm{MHz}, 4 \mathrm{MHz}, 2 \mathrm{MHz}$ and $1 \mathrm{MHz}$ transducer is $\pm 28 \mathrm{MPa}, \pm 18 \mathrm{MPa}, \pm 15 \mathrm{MPa}$ and $\pm 11 \mathrm{MPa}$ respectively. The deviations data are close to the main weld results and confirm that the $L_{C R}$ waves work more accurately, when lower frequencies are employed.

The maximum of residual stress measured by $5 \mathrm{MHz}, 4 \mathrm{MHz}, 2 \mathrm{MHz}$ and $1 \mathrm{MHz}$ transducers is $208.34 \mathrm{MPa}, 181.71$ $\mathrm{MPa}, 164.18 \mathrm{MPa}$ and $79.58 \mathrm{MPa}$ respectively. These results are less than the main weld residual stresses because of lower welding energy during the back weld process.

Since the height of the back weld is $3 \mathrm{~mm}$, the $2 \mathrm{MHz} L_{C_{R}}$ wave (with penetration depth of $2 \mathrm{~mm}$ ) travels close to the root of the back weld. Furthermore, the $1 \mathrm{MHz} L_{C R}$ wave (with penetration depth of $5 \mathrm{~mm}$ ) is influenced by both the back and main weld simultaneously.

Ultrasonic 3D distribution of longitudinal residual stress of the back weld is shown in Fig. 25. All the results of main and back weld show good agreement between $\mathrm{FE}$ and $L_{C R}$ and it can confirm the capability of $F E L_{C R}$ method to evaluate welding residual stress through the thickness. 


\section{Conclusions}

The main goal of this study is evaluating residual stress through the thickness of stainless steel plates with $10 \mathrm{~mm}$ thickness. Finite element welding simulation, hole-drilling method and $L_{C R}$ ultrasonic waves are employed to reach this goal. According to the achieved results, it can be concluded that:

1) The $L_{C R}$ ultrasonic method measures the average of stresses in determined penetration depth of transducers. Therefore, if measuring the stress in an exact distance from the surface is needed, the ultrasonic method is not recommended.

2) Since the penetration depth of $L_{C R}$ wave is limited, both side measurement of thick plates is recommended.

3) The finite element results are in good agreement with welding logic which says the maximum of tensile residual stress is produced in the weld centerline; it will be transformed to compressive stress near the HAZ and finally free stress zone in the parent material.

4) The average results of FE residual stress in $2 \mathrm{~mm}$ from the surface are in good agreement with those of hole-drilling method.

5) The finite element result for residual stress distribution of the weld centerline show a rapid changes in the weld start and end point and a mild increase in the final third of the weld line.

6) Ultrasonic 3D distribution of residual stresses is compared with finite element analysis and shows an acceptable agreement in the main and back weld.

7) The deviation of ultrasonic and FE results is increased by using high frequency transducers.

8) Less agreement between FE and ultrasonic results is observed in HAZ because of its small width and also dimensional changes through the thickness.

9) Improper effect of welding end point on the residual stress is a surface effect and cannot penetrate more than $1 \mathrm{~mm}$.

10) FE and ultrasonic results show that the maximum of tensile residual stress in the back weld is less than the main weld.

11) It is possible to investigate the top, bottom and root of the main and back weld by $L_{C R}$ waves.

According to the results of this study, $F E L_{C R}$ method (which is the combination of finite element welding simulation and ultrasonic stress measurement by $L_{C R}$ waves) can evaluate welding residual stress through the thickness of investigated stainless steel plate. FELCR method can be introduced as the most cost-effective nondestructive method to produce full 3D maps of welding residual stresses. Its requirements are a computer for simulation and ultrasonic equipments (which can be provided at a lower price than the other nondestructive equipments for stress measurement). However, it can nondestructively predict the residual stress through the thickness with verification.

6.

\section{References}

[1] Rossini NS, Dassisti M, Benyounis KY, Olabi AG. Methods of measuring residual stresses in components. J Materials \& Design 2012; 35:572-88. 
[2] Palanichamy $P$, Joseph A, Jayakumar T. Ultrasonic velocity measurements for estimation of grain size in austenitic stainless steel. NDT E Int 1995; 28:179-85.

[3] Hakan GC, Orkun TB. Nondestructive investigation of the effect of quenching and tempering on medium-carbon low alloy steels. Int J Microstruct Mater Prop 2005; 1:5160.

[4] Ploix MA, El Guerjouma R, Moysan J, Corneloup G, Chassignole B. Acoustical characterization of austenitic stainless-steel welds for experimental and modeling. NDT J Soc Adv Sci 2005; 17:76-81.

[5] Hakan GC, Çam i. Comparison of magnetic Barkhausen noise and ultrasonic velocity measurements for microstructure evaluation of SAE 1040 and SAE 4140 steels. Materials Charact 2007; 58:447-54C.

[6] Mohbacher H, Schneider E, Goebbels K. Temperature dependence of third-order elastic constants. In: Copenhagen: Proc 9th international conference on experimental mechanics 1990; 3:1189-97.

[7] Lhémery A, Calmon P, Chatillon S, Gengembre N. Modeling of ultrasonic fields radiated by contact transducer in a component of irregular surface. Ultrasonics 2002; 40:231-6.

[8] Goldak J, Bibby M. Computational Thermal Analysis of Welds. Modeling of Casting and Welding Processes 1988; 4:153-66.

[9] Yan D, Wu A, Silvanus J, Shi Q. Predicting residual distortion of aluminum alloy stiffened sheet after friction stir welding by numerical simulation. J Materials \& Design 2011; 32:2284-91.

[10] Sattari-Far I, Javadi Y. Influence of welding sequence on welding distortions in pipes. Int J of Pressure Vessels and Piping 2008; 85:265-74.

[11] Bray DE, Tang W. Subsurface Stress Evaluation in Steel Plates and Bars with the $\mathrm{L}_{C R}$ Ultrasonic Wave. Nuclear Engineering and Design 2001; 207:231-40.

[12] Goldak J, Akhlaghi M. Computational Welding Mechanics. Springer; 2005.

[13] Lindgren LE. Finite element modelling and simulation of welding part 2: improved material modeling. J Thermal Stress 2001; 24:195-231.

[14] Zhu XK, Chao YJ. Numerical simulation of transient temperature and residual stresses in friction stir welding of $304 \mathrm{~L}$ stainless steel. Journal of Materials Processing Technology 2004; 146: 263-72.

[15] Lindgren LE. Finite Element Modelling and Simulation of Welding Part 1: Increased complexity. J Thermal Stress 2001; 24:141-92.

[16] Deng D, Murakawa H. Numerical simulation of temperature field and residual stress in multi-pass welds in stainless steel pipe and comparison with experimental measurements. Computational Materials Science 2006; 37:269-77.

[17] Qozam H, Chaki S, Bourse G, Robin C, Walaszek H, Bouteille P. Microstructure Effect on the Lcr Elastic Wave for Welding Residual Stress Measurement. Experimental Mechanics 2010; 50:179-85. 
[18] Palanichamy $P$, Vasudevan $M$, Jayakumar T. Measurement of residual stresses in austenitic stainless steel weld joints using ultrasonic technique. Science and Technology of Welding and Joining 2010; 14:166-71.

[19] Masubuchi K, Blodgett OW, Matsui S, Ross FP, Tsai CL. Residual Stresses and Distortion. In Welding Handbook, 9th ed., Vol. 1. Miami: American welding society; 1999, p. 218-64.

[20] Teng TL, Chang PH, Tseng WC. Effect of welding sequences on residual stresses. Computers and Structures 2003; 81:273-86.

[21] Bray DE. Ultrasonic Stress Measurement in Pressure Vessels, Piping and Welds. Journal of Pressure Vessel Technology 2002; 124: 326-35.

[22] Belahcene F, Lu J. Determination of residual stress using critically refracted longitudinal waves and immersion mode. The Journal of Strain Analysis for Engineering Design 2002; 37:13-20.

[23] Lu H, Liu XS, Yang JG, Zhang SP, Fang HY. Ultrasonic stress evaluation on welded plates with Lcr wave. Science and Technology of Welding and Joining 2008; 13:70-4.

[24] Gachia S, Belahcene F, Boubenider F. Residual stresses in AA7108 aluminium alloy sheets joined by friction stir welding. Nondestructive Testing and Evaluation 2009; 24: 301-9.

8. 


\section{List of Table Captions}

Table 1: Welding specifications

Table 2. Acoustoelastic constant $\left(L_{11}\right)$ related to frequency

Table 3: Average of residual stress according to the available test frequencies for the middle plane of specimen $(\mathrm{Z}=300 \mathrm{~mm}$ and $\mathrm{X}=0 \mathrm{~mm})$ 


\section{List of Figure Captions}

Fig. 1.LCR probe for PMMA (plexiglas) wedge on steel by the normal transducers with the same frequency

Fig. 2. Basic finite element model

Fig. 3. Measurement Devices

Fig. 4. Experimental setup to measure the penetration depth of $L_{C R}$ wave

Fig. 5. Overetched section to make the HAZ visible

Fig. 6. Microstructure of a) HAZ and b) Simulated Sample to reproduce HAZ microstructure (Electro-etched with $10 \%$ Oxalic acid for 2 min at $200 X)$

Fig. 7. Tensile test to evaluate the acoustoelastic constant $\left(L_{11}\right)$

Fig. 8. Result of Tensile test to evaluate the acoustoelastic constant of $\mathrm{L}_{C R}$ wave by $1 \mathrm{MHz}$ Transducer

Fig. 9. Ultrasonic Measurement and Plate Dimensions

Fig. 10. FE Distribution of Residual Stress through the Thickness in $Z=300 \mathrm{~mm}$ and $X=0 \mathrm{~mm}$

Fig. 11. FE Results for the Longitudinal Residual Stress in Different Depths (correspond to the integration points of the elements) from the Top Surface in a) Main Weld and b) Back Weld

Fig. 12. FE Results for the Averages of Longitudinal Residual Stress for the Related Test Frequencies in a) Main Weld and b) Back Weld

Fig. 13. The Comparison of Finite Element and Hole Drilling Method according to Residual Stress

Fig. 14. Hole-Drilling Method

Fig. 15. FE Results for the Longitudinal Residual Stress in the Weld Line in a) Main Weld and b) Back Weld

Fig. 16. Comparison of $5 \mathrm{MHz}$ Transducer and FE Results in Residual Stress Measurement of Main Weld in the a) Last Test Section and b) Middle Test Section

Fig. 17. Comparison of $4 \mathrm{MHz}$ Transducer and FE Results in Residual Stress Measurement of Main Weld in the a) Last Test Section and b) Middle Test Section

Fig. 18. Comparison of $2 \mathrm{MHz}$ Transducer and FE Results in Residual Stress Measurement of Main Weld in the a) Last Test Section and b) Middle Test Section

Fig. 19. Comparison of $1 \mathrm{MHz}$ Transducer and FE Results in Residual Stress Measurement of Main Weld in the a) Last Test Section and b) Middle Test Section

Fig. 20. 3D Distribution of Longitudinal Residual Stress in the Main Weld which is Measured by $L_{C R}$ Transducers of a) $5 \mathrm{MHz}$, b) $4 \mathrm{MHz}$, c) $2 \mathrm{MHz}$ and d) $1 \mathrm{MHz}$

Fig. 21. Comparison of $5 \mathrm{MHz}$ Transducer and FE Results in Residual Stress Measurement of Back Weld in the a) Last Test Section and b) Middle Test Section

Fig. 22. Comparison of $4 \mathrm{MHz}$ Transducer and FE Results in Residual Stress Measurement of Back Weld in the a) Last Test Section and b) Middle Test Section

Fig. 23. Comparison of $2 \mathrm{MHz}$ Transducer and FE Results in Residual Stress Measurement of Back Weld in the a) Last Test Section and b) Middle Test Section

Fig. 24. Comparison of $1 \mathrm{MHz}$ Transducer and FE Results in Residual Stress Measurement of Back Weld in the a) Last Test Section and b) Middle Test Section

Fig. 25. 3D Distribution of Longitudinal Residual Stress in the Back Weld which is Measured by $L_{C R}$ Transducers of a) $5 \mathrm{MHz}$, b) $4 \mathrm{MHz}$, c) $2 \mathrm{MHz}$ and d) $1 \mathrm{MHz}$ 


\section{Tables}

Table 1: Welding specifications

\begin{tabular}{|c|c|c|c|c|}
\hline & $\begin{array}{l}\text { Weldin } \\
\text { g } \\
\text { Voltage } \\
\text { (V) }\end{array}$ & $\begin{array}{l}\text { Weldin } \\
\text { g } \\
\text { Current } \\
\text { (A) }\end{array}$ & $\begin{array}{l}\text { Welding } \\
\text { Speed } \\
\text { (cm min } \\
\text { 1) }\end{array}$ & $\begin{array}{l}\text { Electrode } \\
\text { Material }\end{array}$ \\
\hline $\begin{array}{l}\text { Mai } \\
n \\
\text { Wel } \\
d\end{array}$ & 28 & 420 & 60 & ER308L \\
\hline $\begin{array}{l}\text { Back } \\
\text { Wel } \\
\text { d }\end{array}$ & 24 & 400 & 95 & ER308L \\
\hline
\end{tabular}

Table 2 . Acoustoelastic constant $\left(L_{11}\right)$ related to frequency

\begin{tabular}{c|ccc}
\hline Frequency & Parent Material (PM) & Heat Affected Zone (HAZ) & Melted Zone (MZ) \\
\hline $1 \mathrm{MHz}$ & 2.17 & 1.937 & 2.558 \\
$2 \mathrm{MHz}$ & 2.102 & 1.839 & 2.452 \\
$4 \mathrm{MHz}$ & 2.011 & 1.829 & 2.263 \\
$5 \mathrm{MHz}$ & 2.132 & 1.96 & 2.462 \\
\hline Average & 2.111 & 1.8808 & 2.4244 \\
\hline
\end{tabular}

Table 3: Average of residual stress according to the available test frequencies for the middle plane of specimen ( $\mathrm{Z}=300 \mathrm{~mm}$ and $\mathrm{X}=0 \mathrm{~mm}$ )

\begin{tabular}{ccccc}
\hline & $5 \mathrm{MHz}(1 \mathrm{~mm})$ & $4 \mathrm{MHz}(1.5 \mathrm{~mm})$ & $2 \mathrm{MHz}(2 \mathrm{~mm})$ & $1 \mathrm{MHz}(5 \mathrm{~mm})$ \\
\hline Main Weld & 208.6534 & $209.7938 \mathrm{MPa}$ & $200.18 \mathrm{MPa}$ & 142.9795 \\
(Top Surface) & $\mathrm{MPa}$ & & $\mathrm{MPa}$ \\
Back Weld & 164.7977 & $156.9695 \mathrm{MPa}$ & 144.8366 & $68.7137 \mathrm{MPa}$ \\
(Bottom Surface) & $\mathrm{MPa}$ & $\mathrm{MPa}$ & \\
\hline
\end{tabular}




\section{Figures}

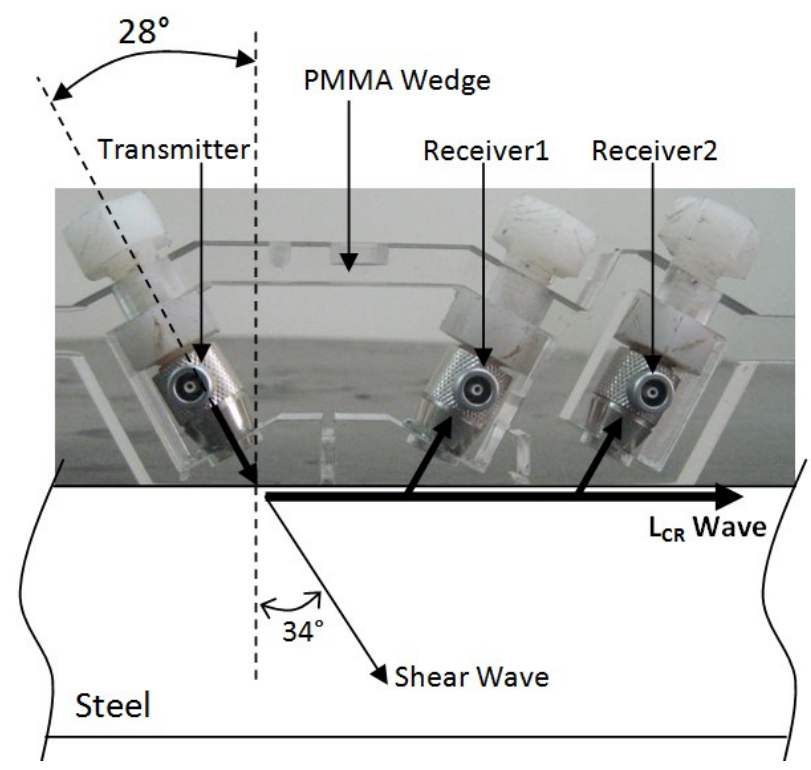

Fig. 1.LcR probe for PMMA (plexiglas) wedge on steel by the normal transducers with the same frequency

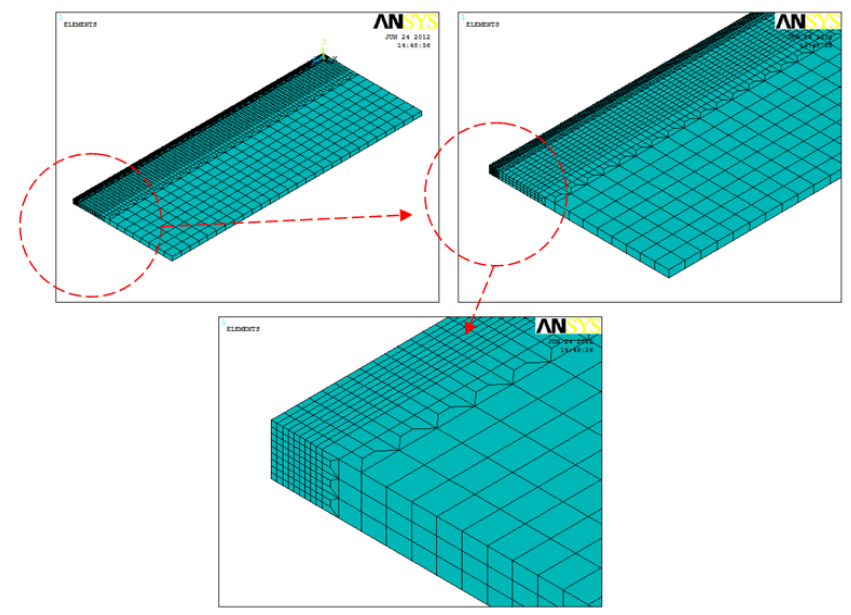

Fig. 2. Basic finite element model 
1) Measuring Table

2) Ultrasonic Box

3) Tested Plate

4) Ultrasonic Software

5) TOF Measuring

Element

6) Guide Rails

7) Perforated Sheet

8) Driver Screw

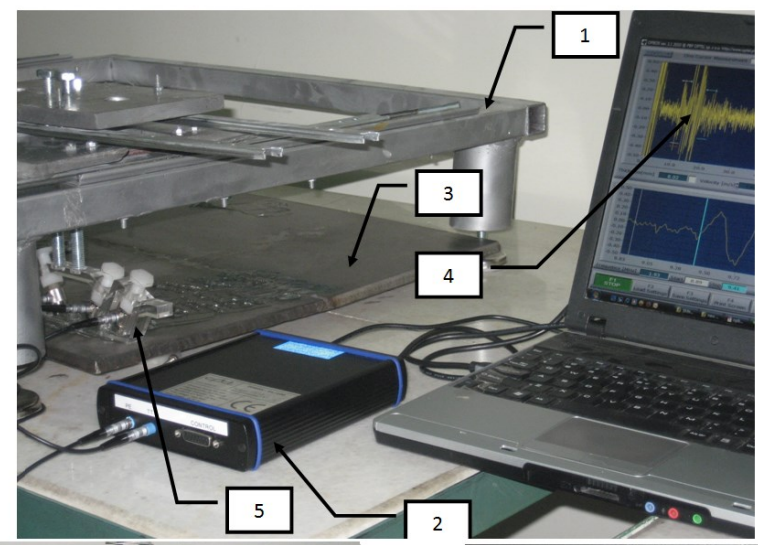

9) Ruler

10) Pressure Screw

11) Adjusting Screw

12) Plastic Screws

13) Plexiglas Wedge

14) Transmitter Transducer

15) Receiver Transducer 1

16) Receiver Transducer2
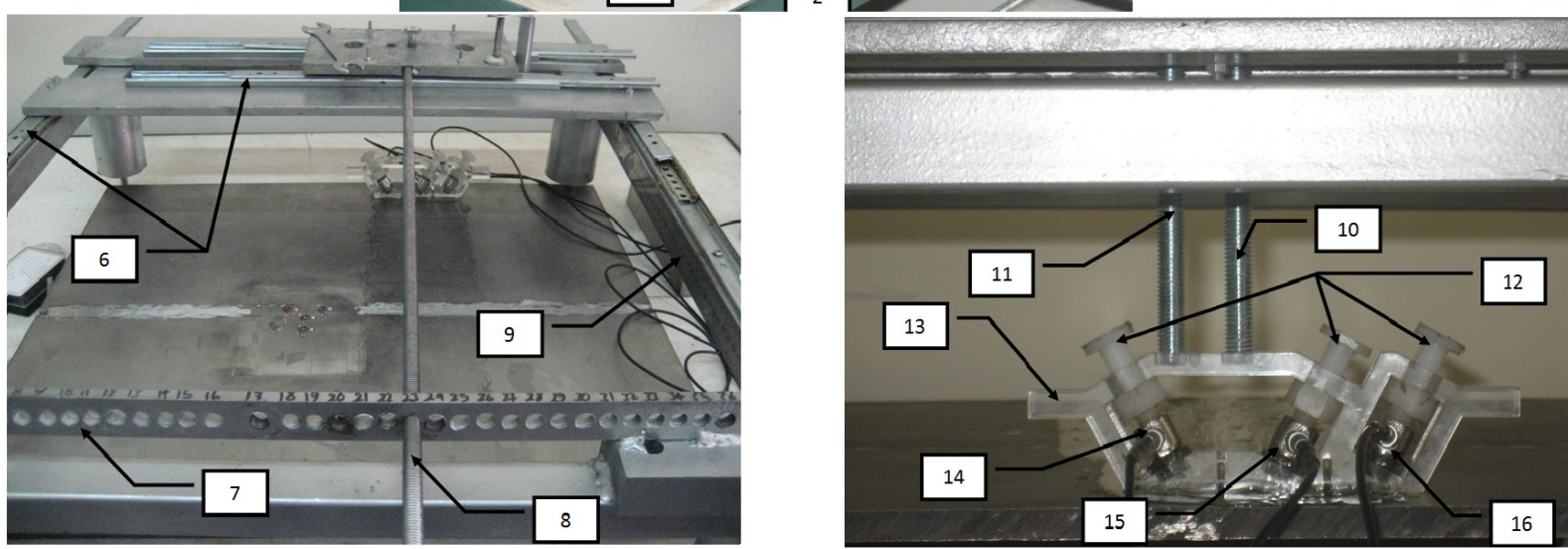

Fig. 3. Measurement Devices

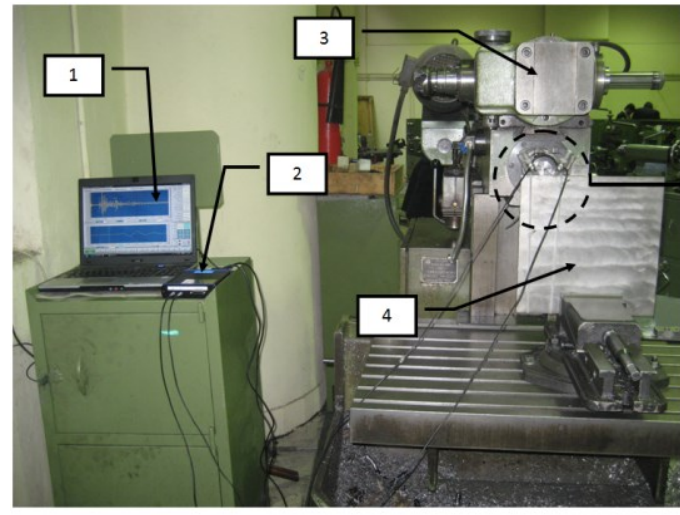

1) Ultrasonic Software

2) Ultrasonic Box

3) Milling

Machine

4) Stainless Steel

Plate

5) Plexiglas

Wedges

6) Transmitter

Transducer

7) Receiver

Transducer

8) Milling Tool

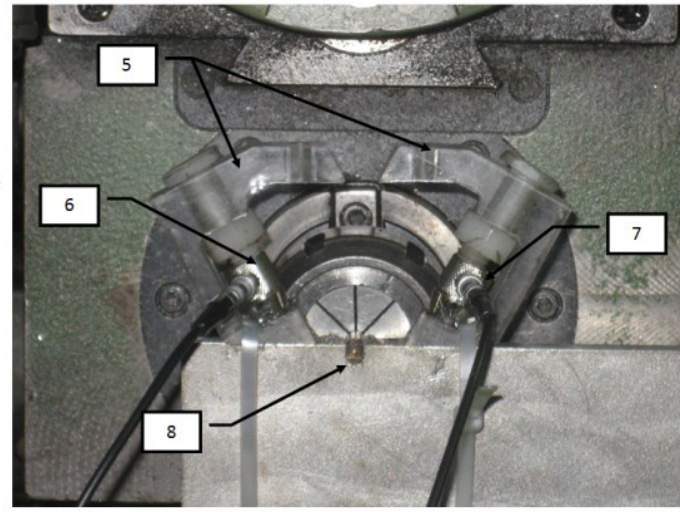

Fig. 4. Experimental setup to measure the penetration depth of $L_{C R}$ wave 


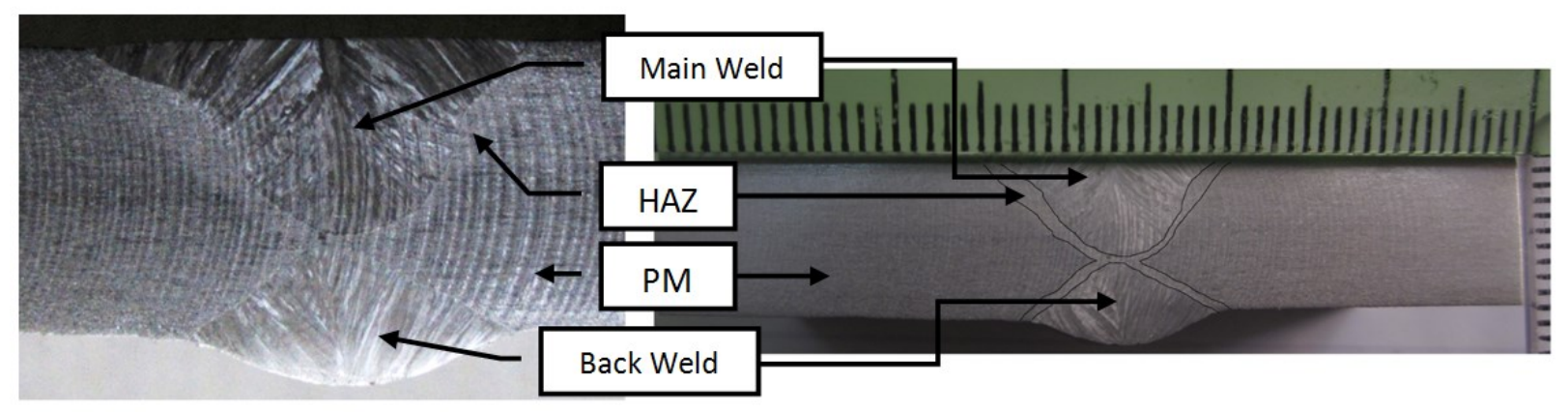

Fig. 5. Overetched section to make the HAZ visible

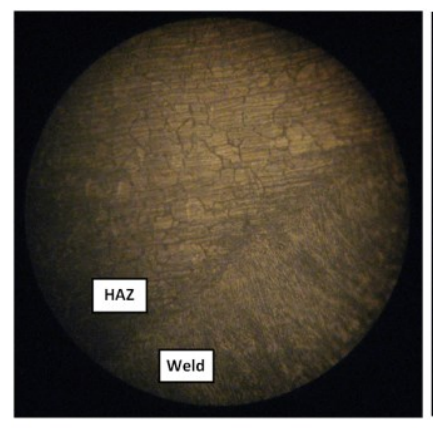

(a)

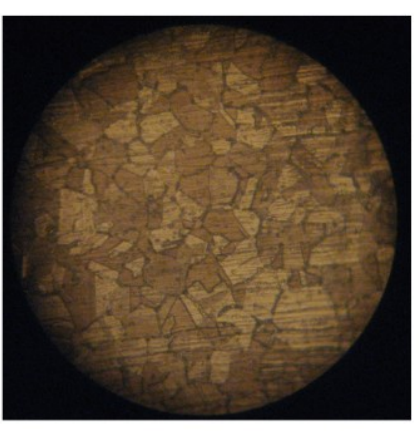

(b)

Fig. 6. Microstructure of a) HAZ and b) Simulated Sample to reproduce HAZ microstructure

(Electro-etched with 10\% Oxalic acid for 2 min at 200X)
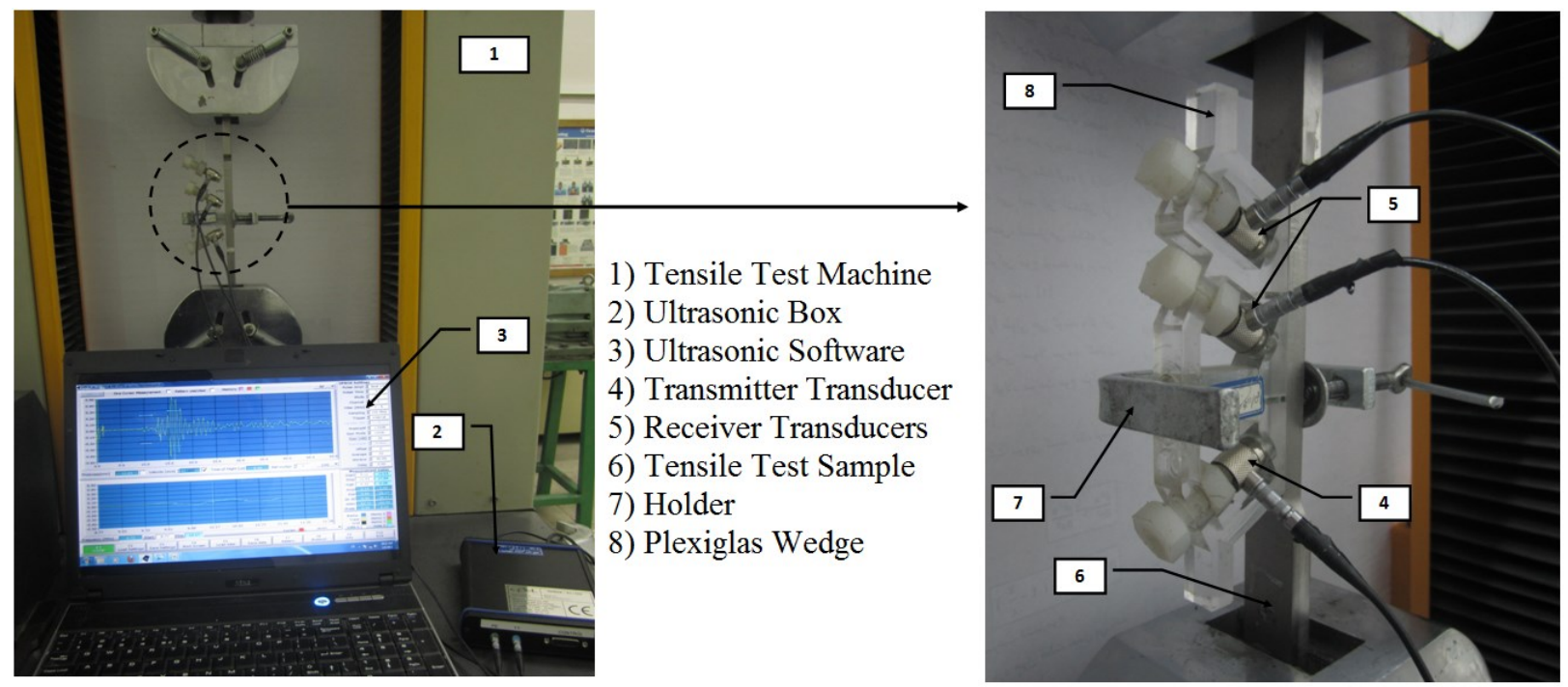

Fig. 7. Tensile test to evaluate the acoustoelastic constant $\left(L_{11}\right)$ 


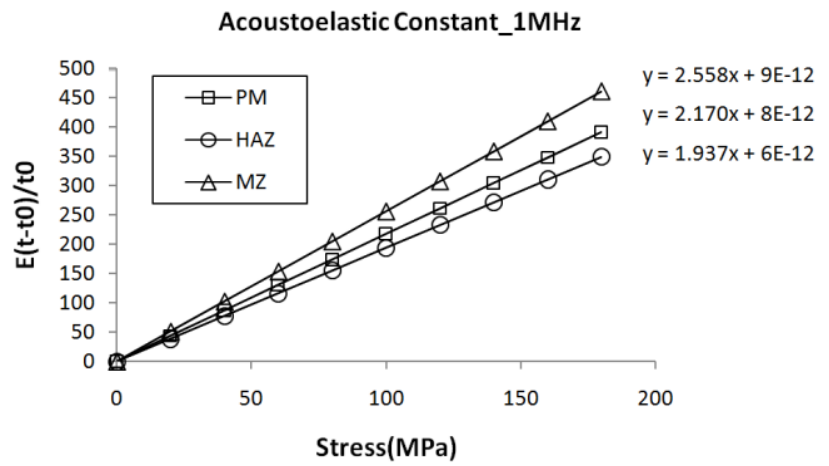

Fig. 8. Result of Tensile test to evaluate the acoustoelastic constant of $\mathrm{LCR}_{\mathrm{R}}$ wave by $1 \mathrm{MHz}$ Transducer

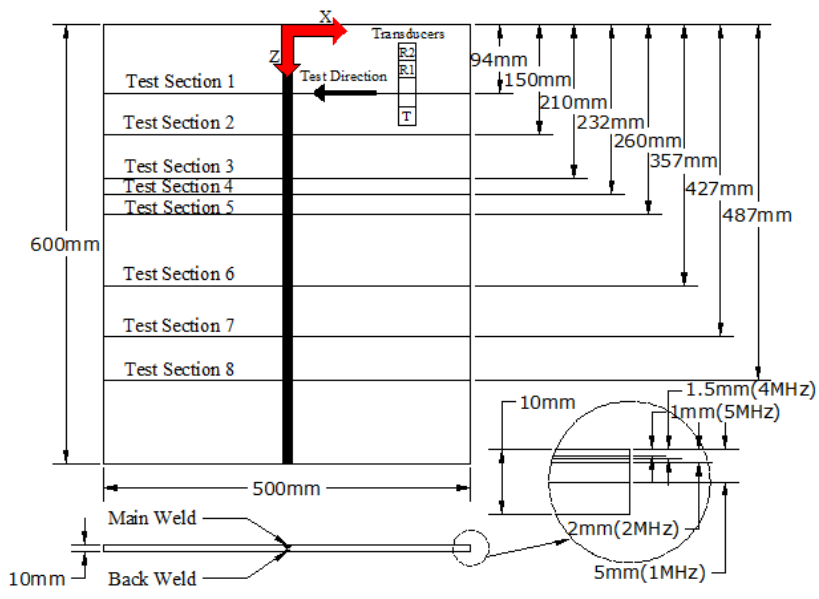

Fig. 9. Ultrasonic Measurement and Plate Dimensions

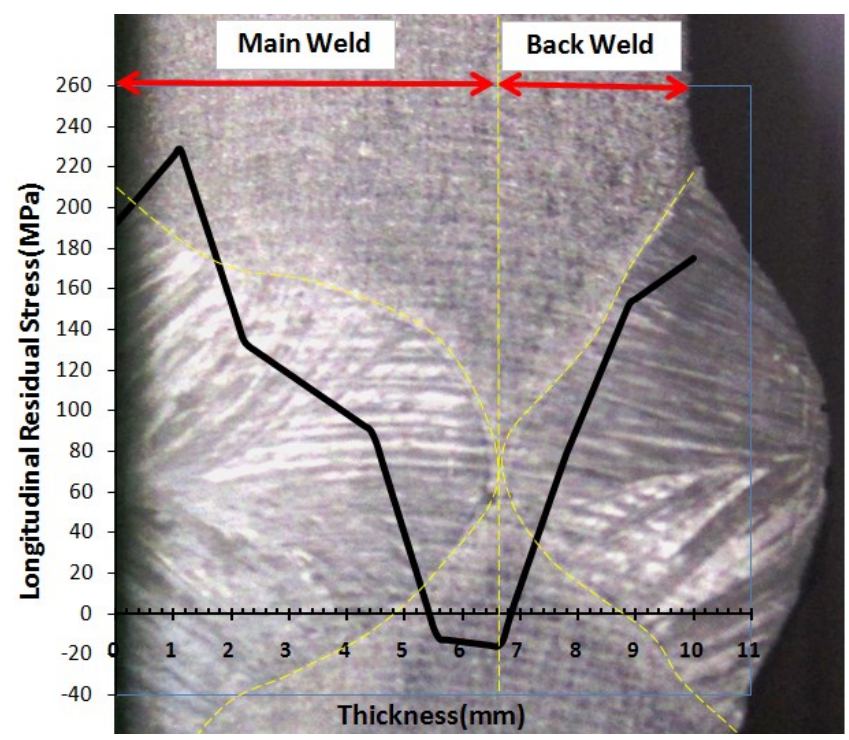

Fig. 10. FE Distribution of Residual Stress through the Thickness in $Z=300 \mathrm{~mm}$ and $X=0 \mathrm{~mm}$ 
Main Weld

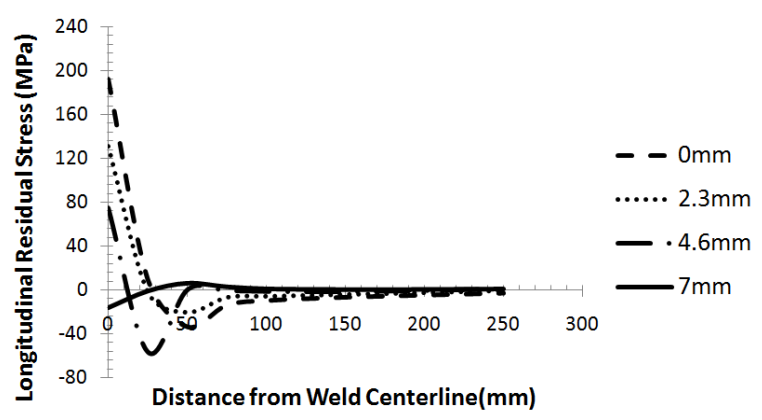

(a)

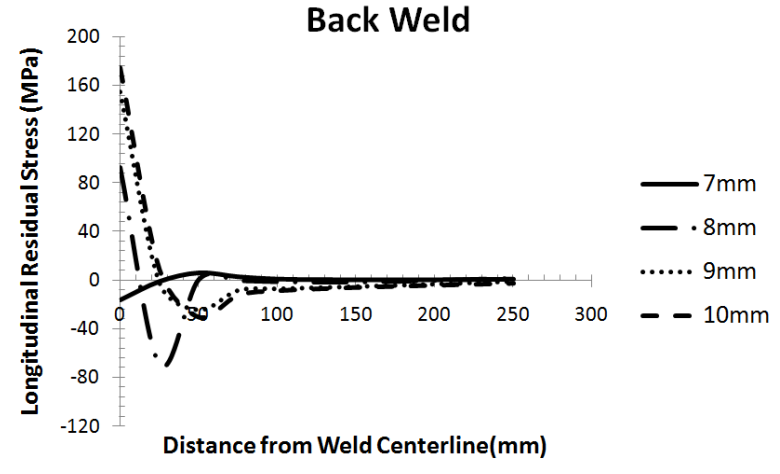

(b)

Fig. 11. FE Results for the Longitudinal Residual Stress in Different Depths (correspond to the integration points of the elements) from the Top Surface in a) Main Weld and b) Back Weld

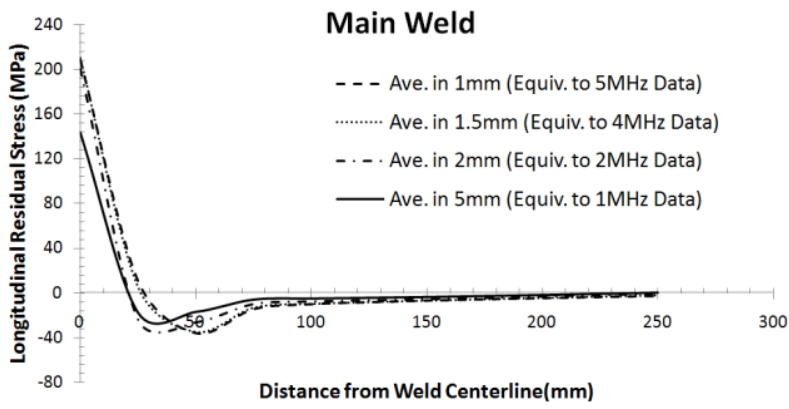

(a)

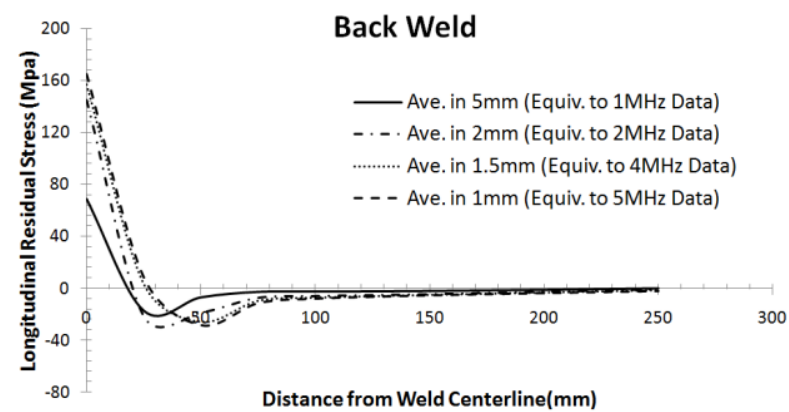

(b)

Fig. 12. FE Results for the Averages of Longitudinal Residual Stress for the Related Test Frequencies in a) Main Weld and b) Back Weld

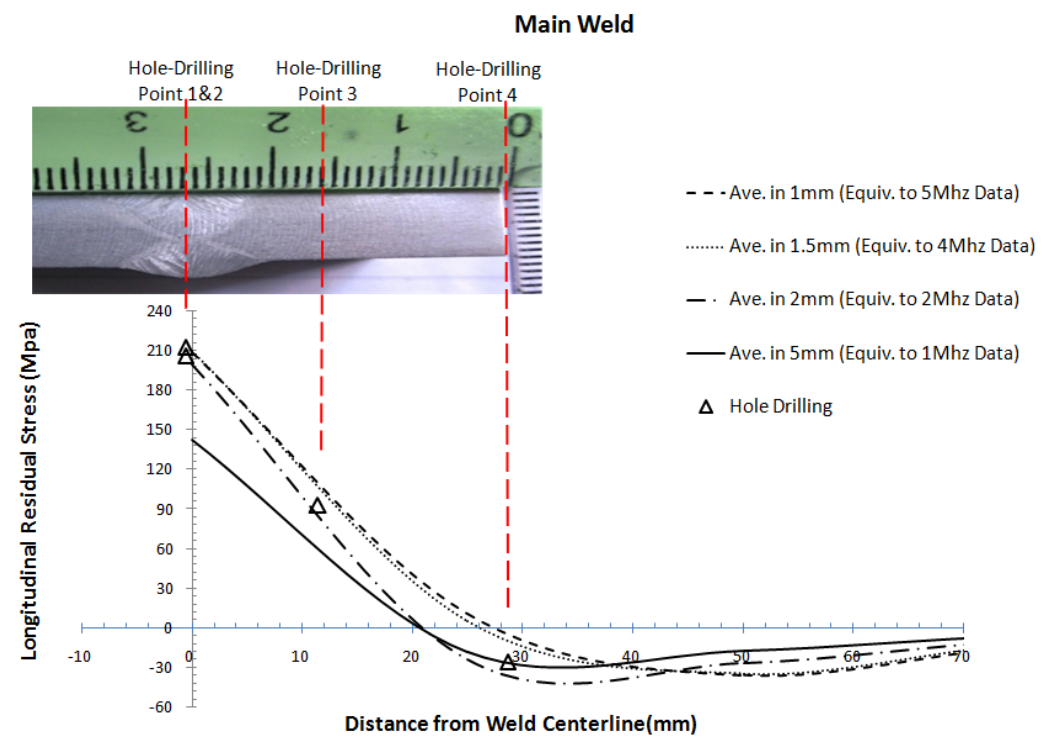


Fig. 13. The Comparison of Finite Element and Hole Drilling Method according to Residual Stress
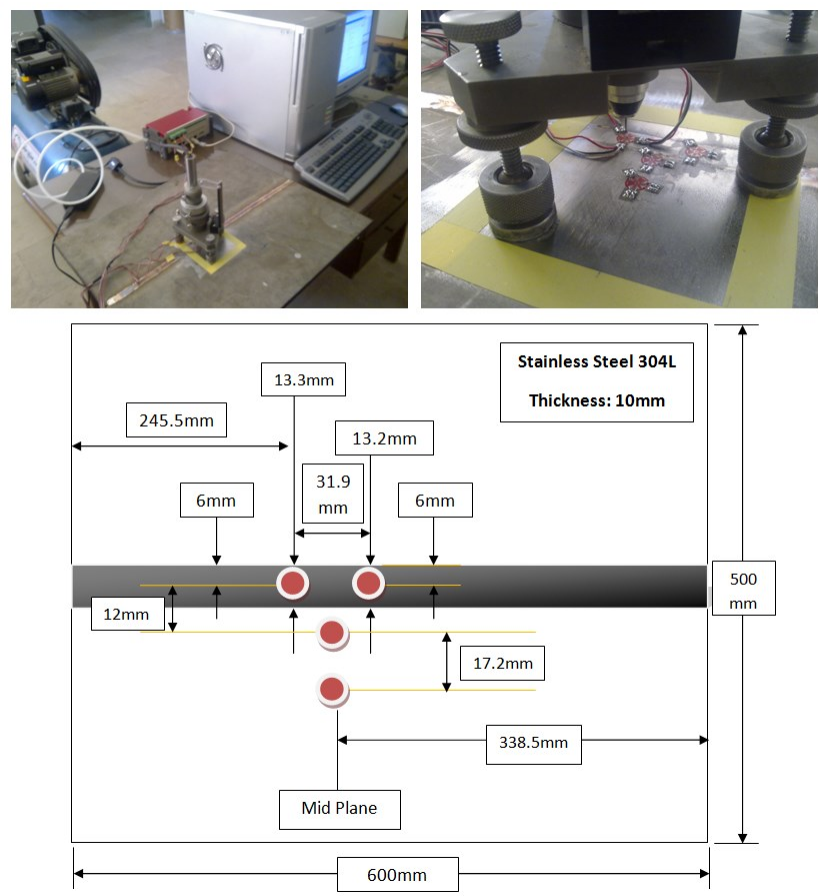

Fig. 14. Hole-Drilling Method

Main Weld

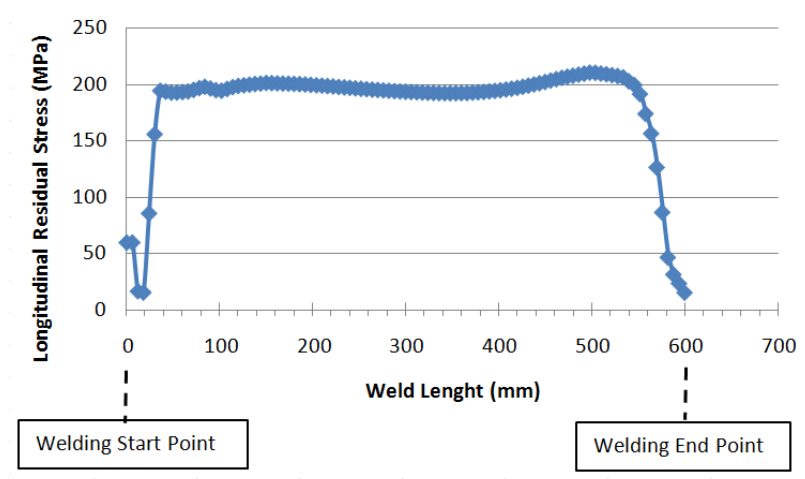

(a)
Back Weld

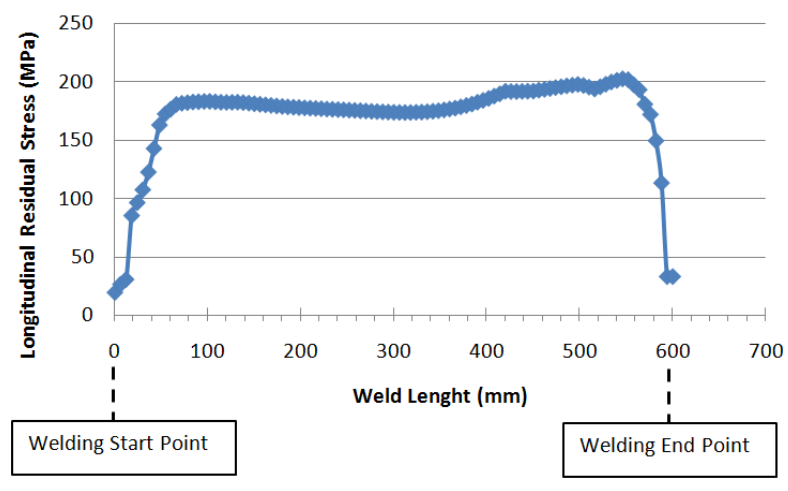

(b)

Fig. 15. FE Results for the Longitudinal Residual Stress in the Weld Line in a) Main Weld and b) Back Weld 
MAIN WELD_5MHz_Test Section8

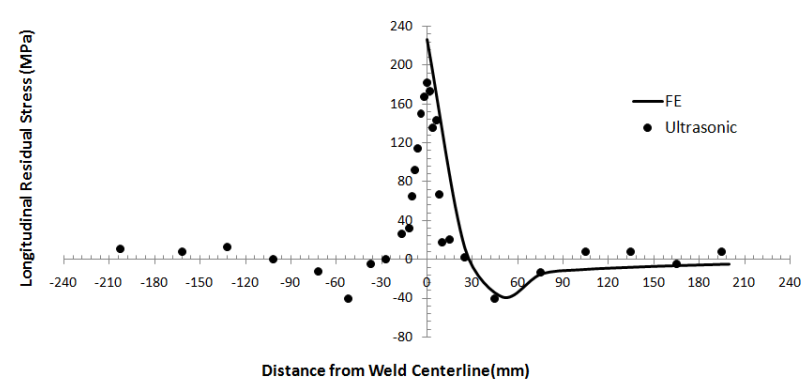

(a)
MAIN WELD_5MHz_Test Section5

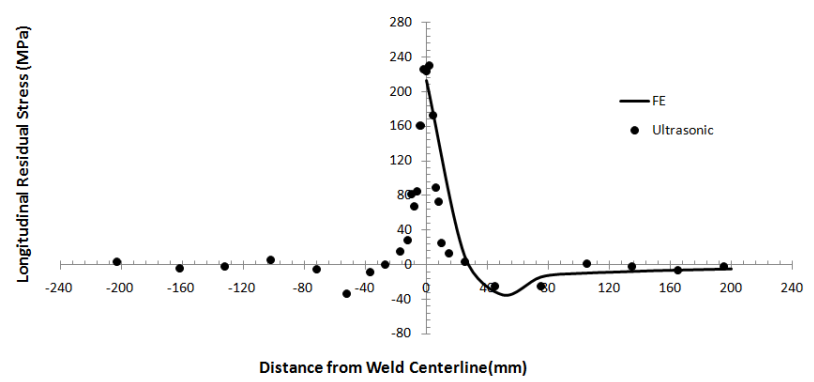

(b)

Fig. 16. Comparison of $5 \mathrm{MHz}$ Transducer and FE Results in Residual Stress Measurement of Main Weld in the a) Last Test Section and b) Middle Test Section

MAIN WELD_4MHz_Test Section8

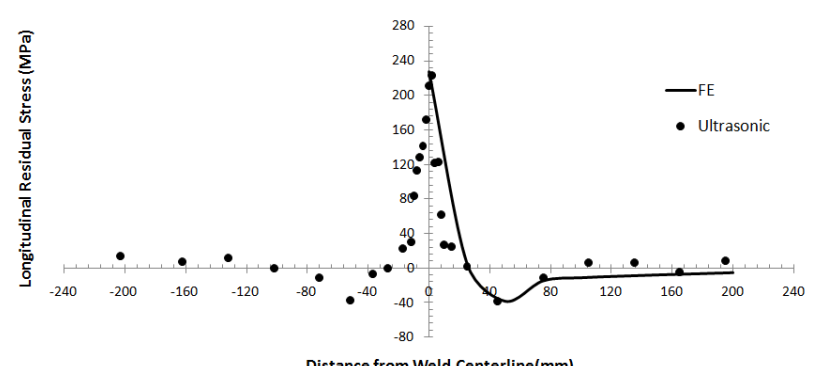

(a)
MAIN WELD_4MHz_Test Section5

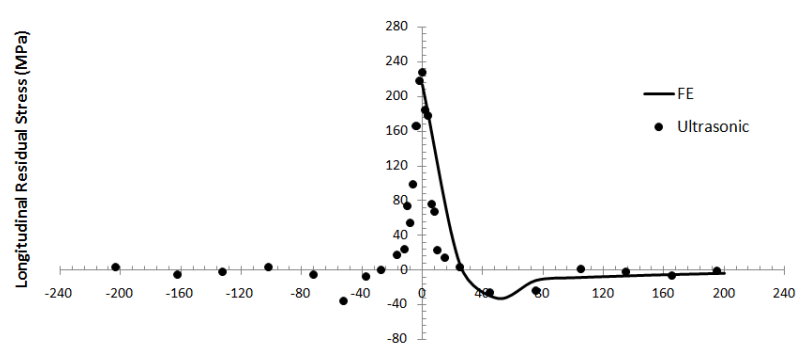

Distance from Weld Centerline(mm)

(b)

Fig. 17. Comparison of $4 \mathrm{MHz}$ Transducer and FE Results in Residual Stress Measurement of Main Weld in the Last Test Section and b) Middle Test Section

MAIN WELD_2MHz_Test Section8

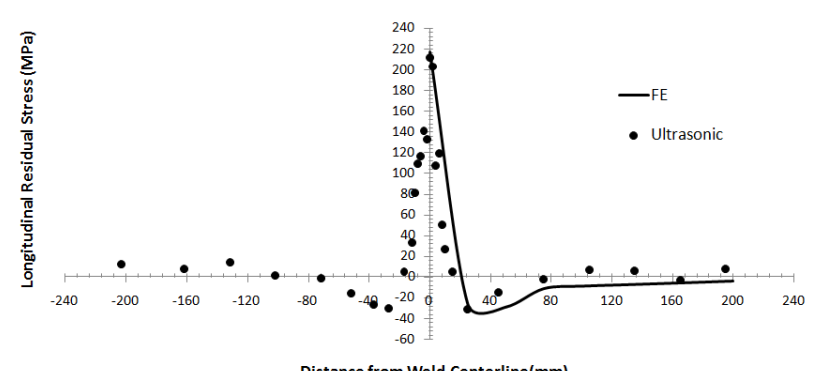

(a)
MAIN WELD_2MHz_Test Section5

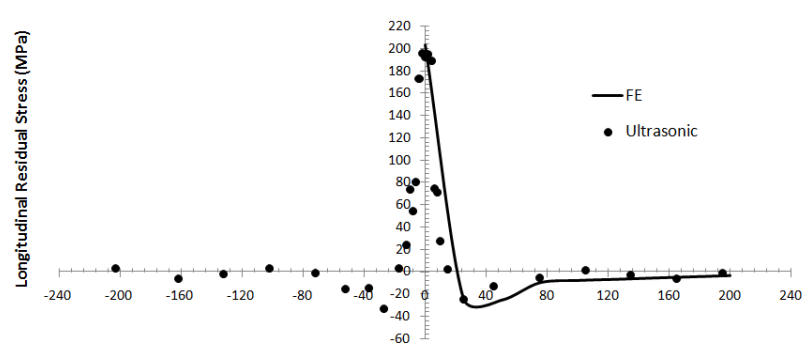

Distance from Weld Centerline(mm)

(b)

Fig. 18. Comparison of $2 \mathrm{MHz}$ Transducer and FE Results in Residual Stress Measurement of Main Weld in the Last Test Section and b) Middle Test Section 
MAIN WELD_1MHz_Test Section8

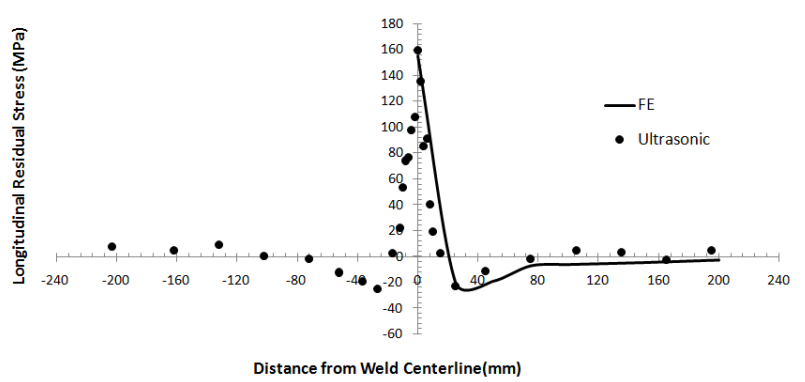

(a)
MAIN WELD_1MHz_Test Section5

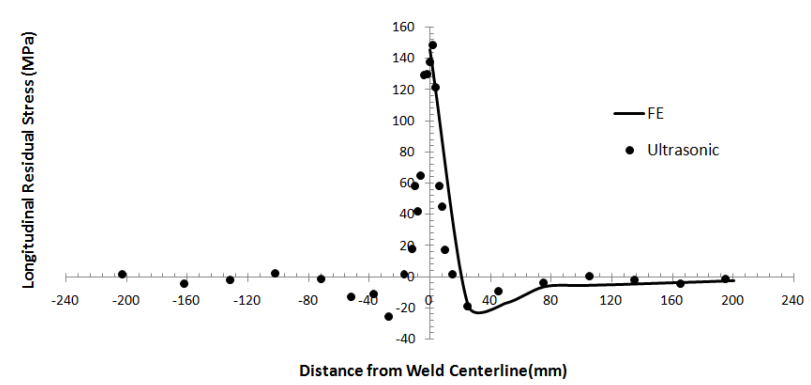

(b)

Fig. 19. Comparison of $1 \mathrm{MHz}$ Transducer and FE Results in Residual Stress Measurement of Main Weld in the a) Last Test Section and b) Middle Test Section

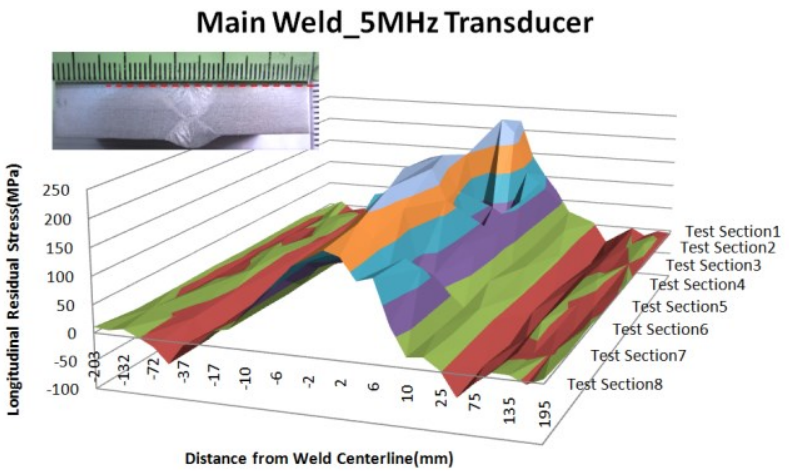

(a)

Main Weld_2MHzTransducer

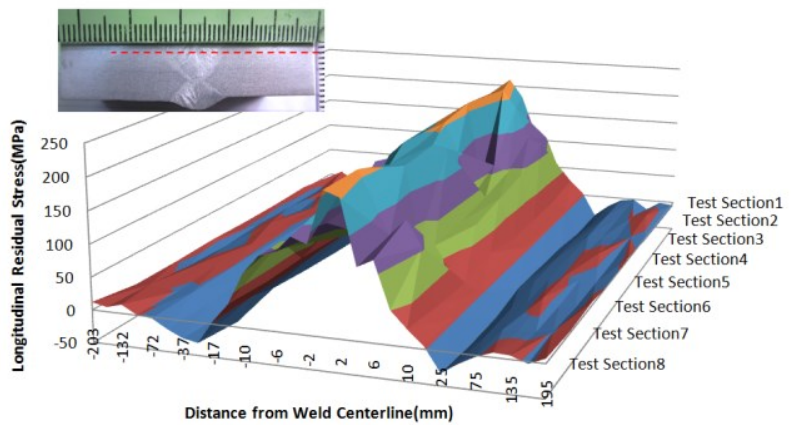

(c)

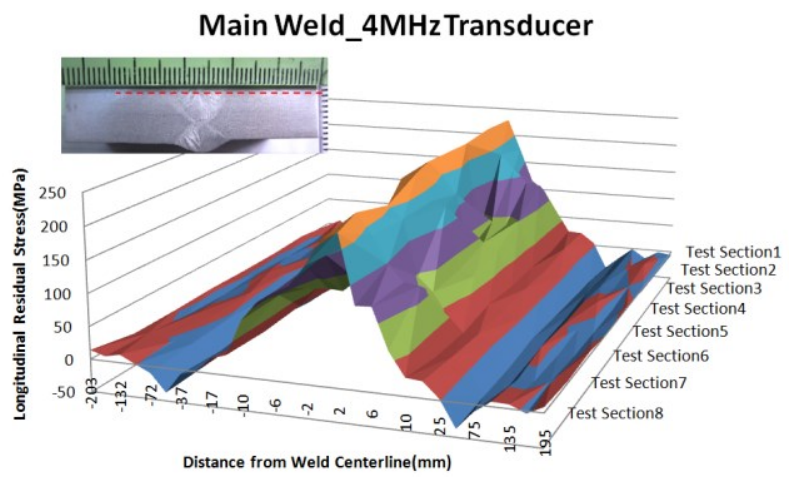

(b)

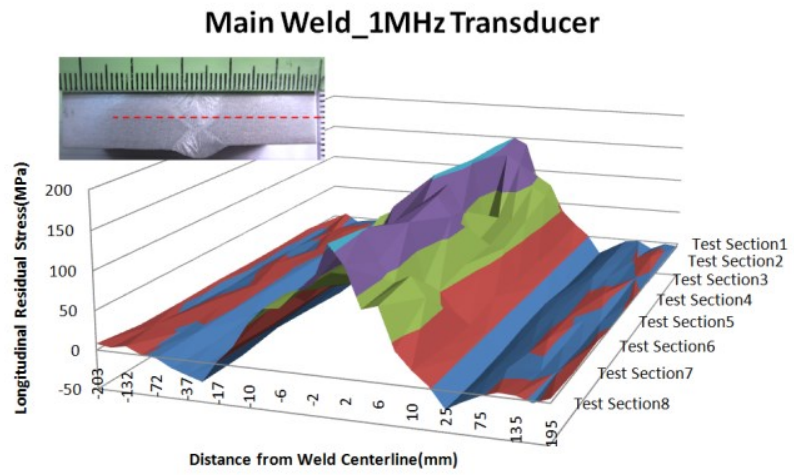

(d)

Fig. 20. 3D Distribution of Longitudinal Residual Stress in the Main Weld which is Measured by $L_{C R}$ Transducers of a) $5 \mathrm{MHz}$, b) $4 \mathrm{MHz}$, c) $2 \mathrm{MHz}$ and d) $1 \mathrm{MHz}$ 


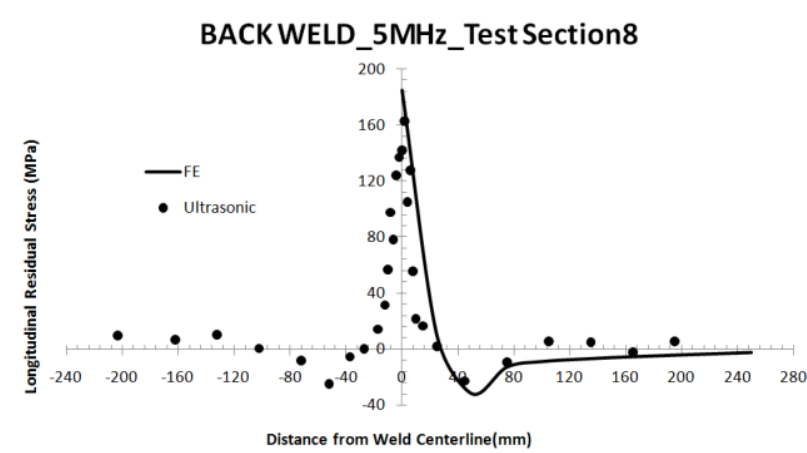

(a)
BACK WELD_5MHz_Test Section5

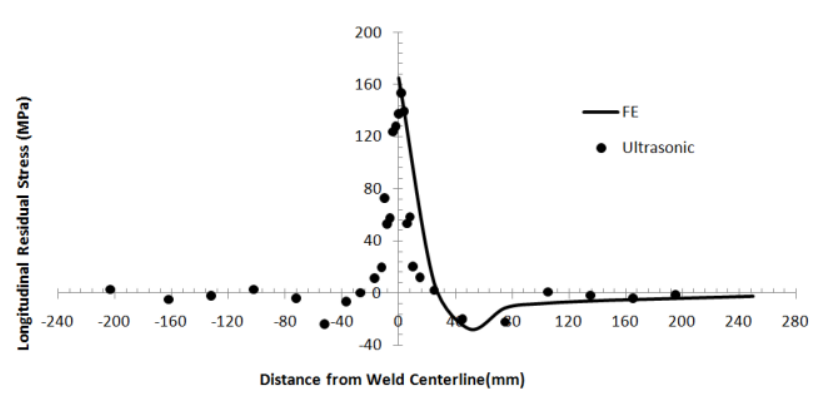

(b)

Fig. 21. Comparison of $5 \mathrm{MHz}$ Transducer and FE Results in Residual Stress Measurement of Back Weld in the a) Last Test Section and b) Middle Test Section

\section{BACK WELD_4MHz_Test Section8}

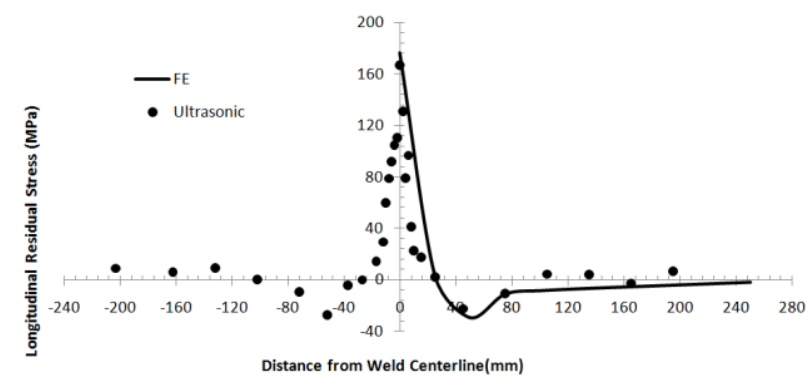

(a)
BACK WELD_4MHz_Test Section5

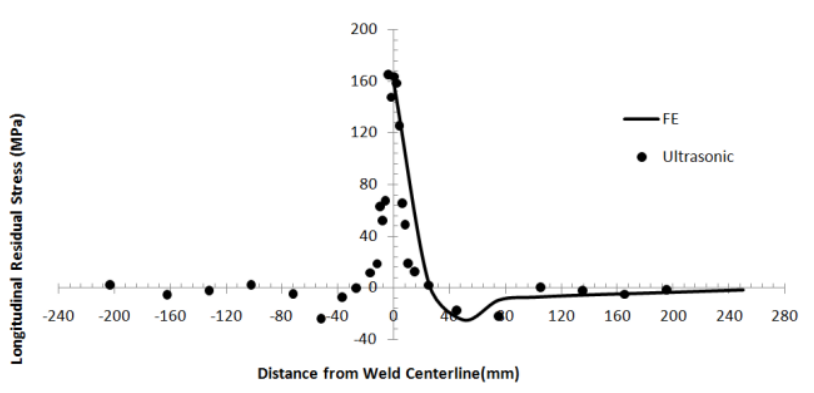

(b)

Fig. 22. Comparison of $4 \mathrm{MHz}$ Transducer and FE Results in Residual Stress Measurement of Back Weld in the a) Last Test Section and b) Middle Test Section

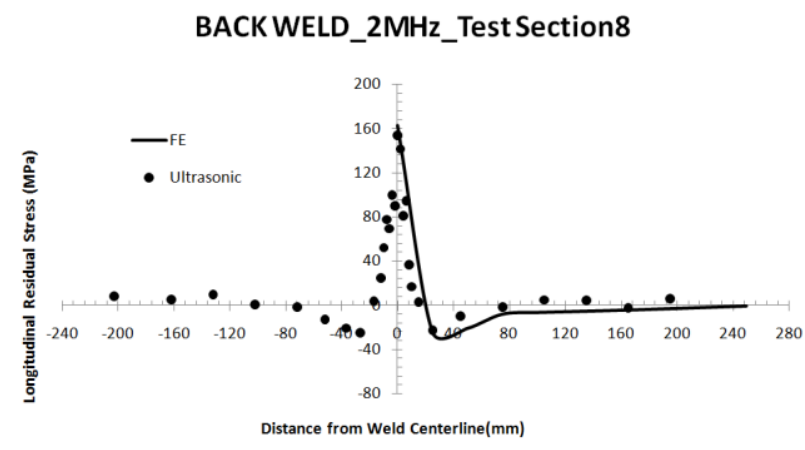

(a)

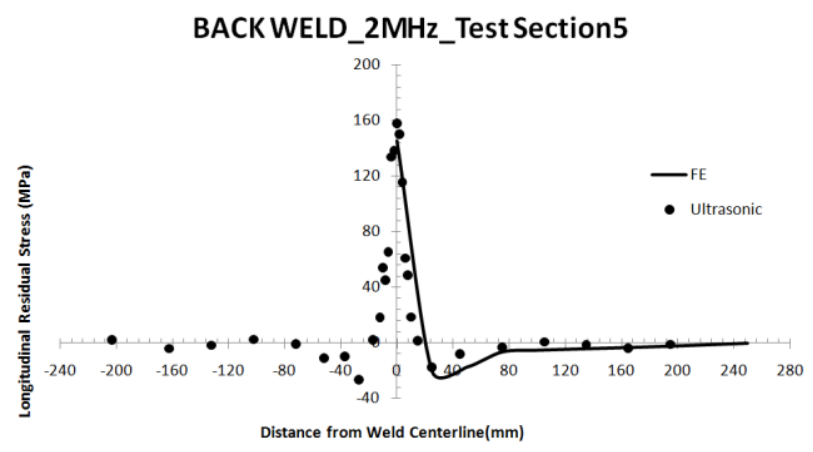

(b)

Fig. 23. Comparison of $2 \mathrm{MHz}$ Transducer and FE Results in Residual Stress Measurement of Back Weld in the a) Last Test Section and b) Middle Test Section 
BACK WELD_1MHz_Test Section8

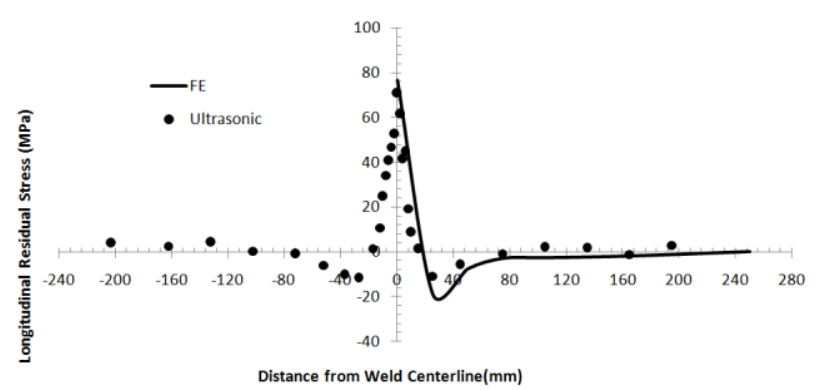

(a)
BACK WELD_1MHz_Test Section5

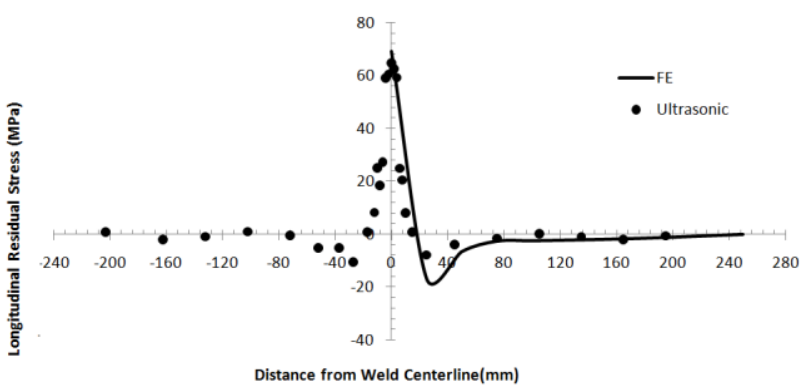

(b)

Fig. 24. Comparison of $1 \mathrm{MHz}$ Transducer and FE Results in Residual Stress Measurement of Back Weld in the a) Last Test Section and b) Middle Test Section

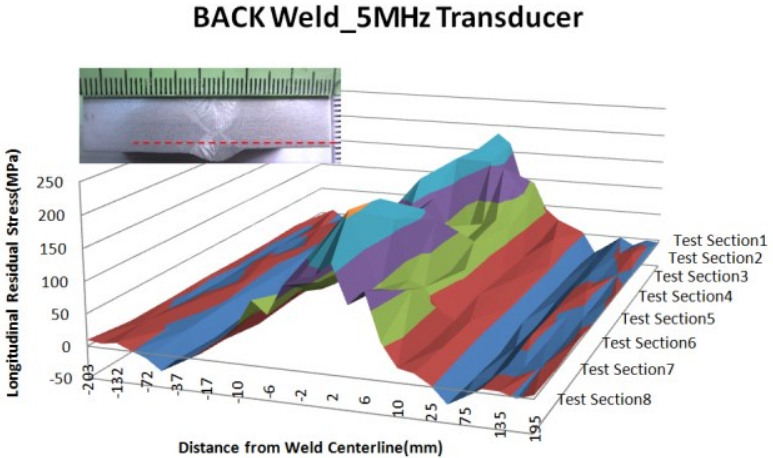

(a)

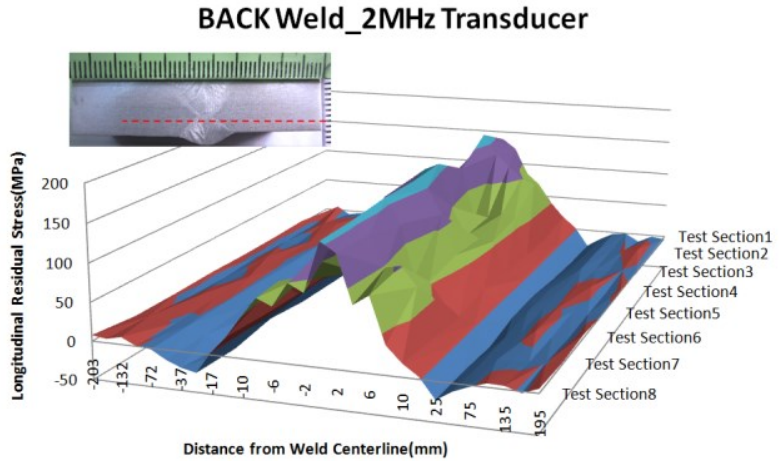

(c)

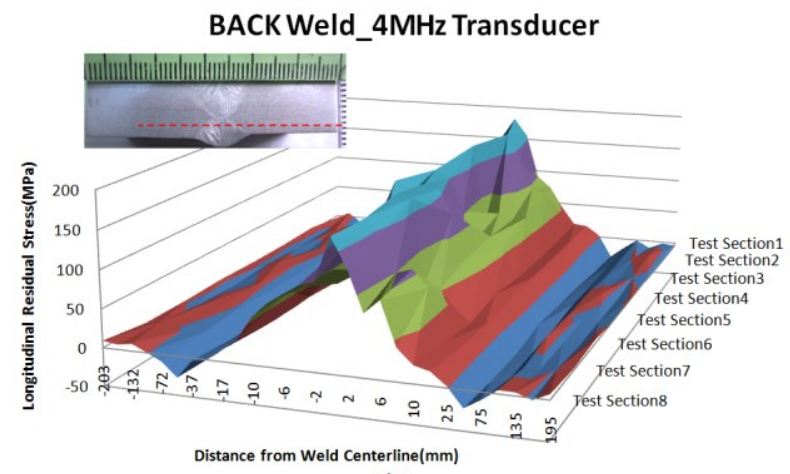

(b)

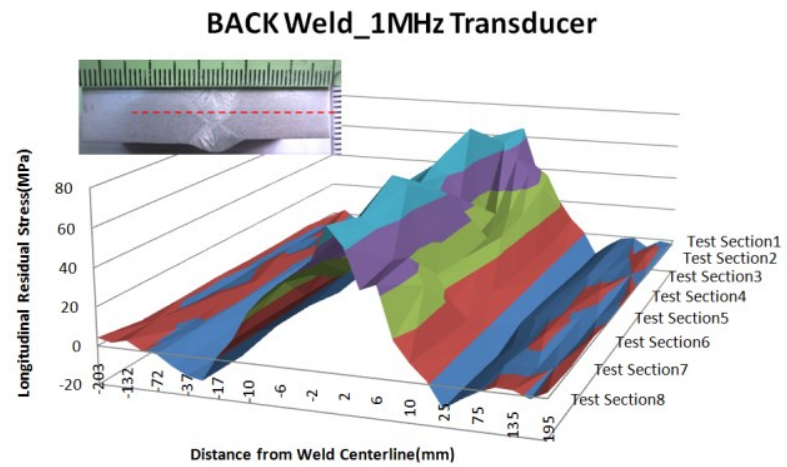

(d)

Fig. 25. 3D Distribution of Longitudinal Residual Stress in the Back Weld which is Measured by $L_{C R}$ Transducers of a) $5 \mathrm{MHz}$, b) $4 \mathrm{MHz}$, c) $2 \mathrm{MHz}$ and d) $1 \mathrm{MHz}$

13. 